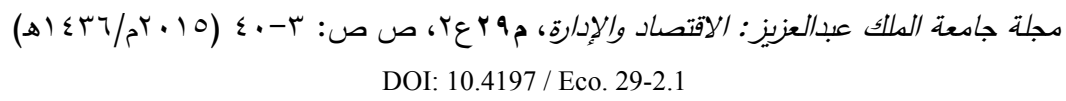

\title{
معوقات التخطيط الاستراتيجي في الجامعات السعودية
}

و محمد الصغير قاسم الشعيبي أستاز مشارك

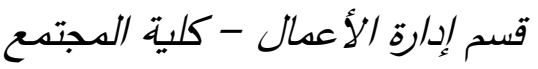

جامعة الملك خالد - أبها

المدلكة العربية السعودية الماكية

dralsheabi@gmail.com

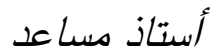

سليمان بن عبدالرحمن آل الثيخ

قسم إدارة الأعمال - كلية الاقتصاد والإدارة

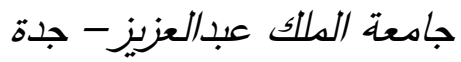

المدلكة العربية السعودية المباية

salalsheikh@kau.edu.sa

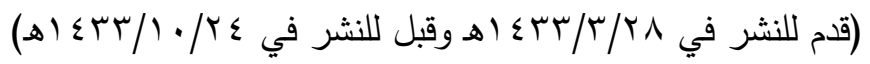

المستخلص. هدفت هذه الدراسة للتعرف على معوقات التخطيط

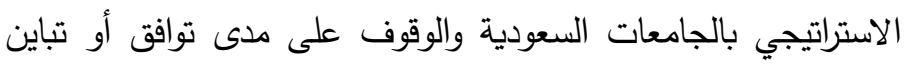

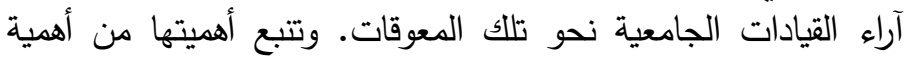

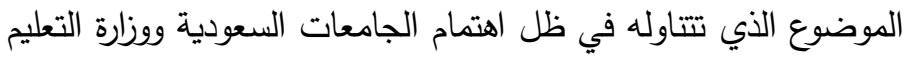

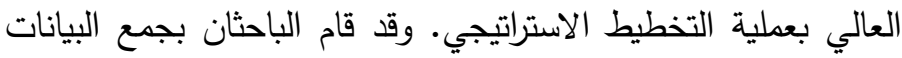

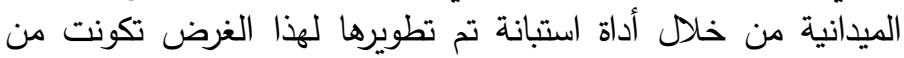

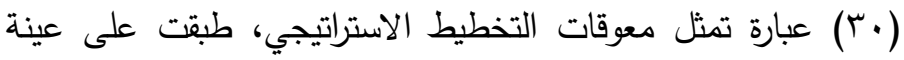

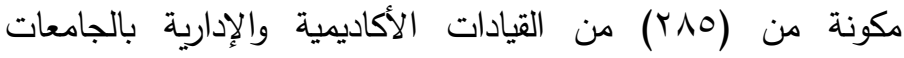

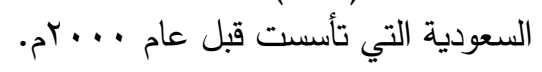

أكدت الدراسة وجود مجموعة كبيرة من الأسباب التي تعوق عملية

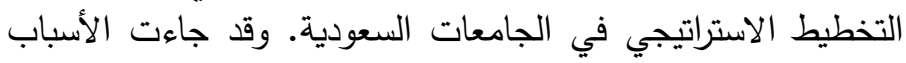

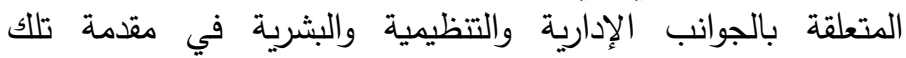

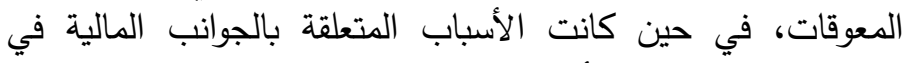
مؤخرة تلك المعوقات. وأخيرًا كثفت الدراسة عن وجود تباين واضح 
بين آراء القيادات من جامعة إلى أخرى نحو درجة تأثير معوقات التخطيط الاستراتيجي عليها.

واختتمت الدراسة بمجموعة من التوصيات يأتي في مقدمتها التأكيد

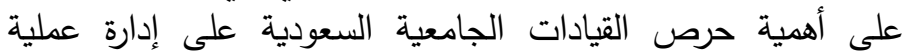

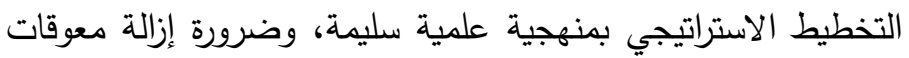

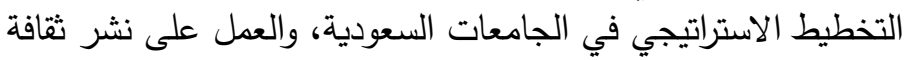
التخطيط الاستراتيجي بها.

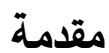

بدأ استخدام التخطيط الاستراتيجي في التعليم العالي بعد محاولات عديدة

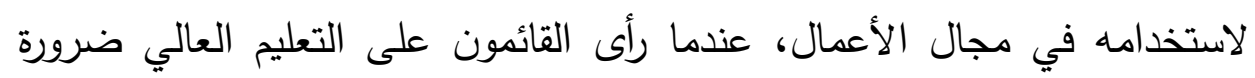

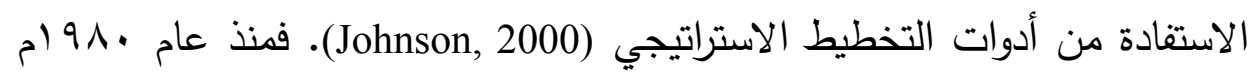

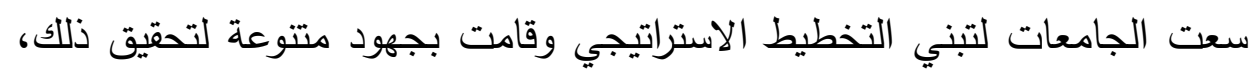
وقد جاء اهتمام الجامعات بالتخطيط الاستراتيجي نتيجة للتحديات العديدة التي

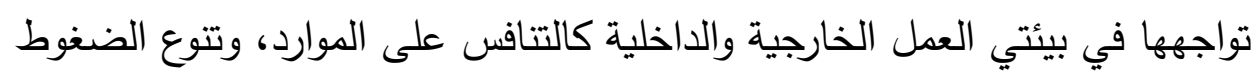

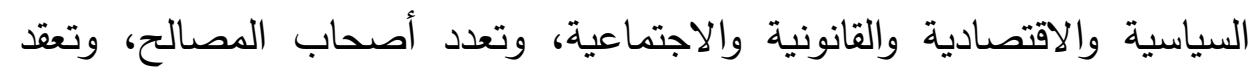

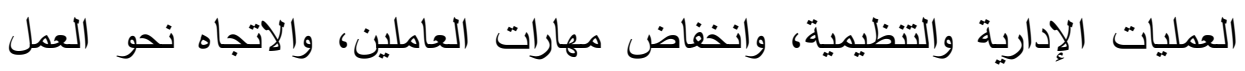

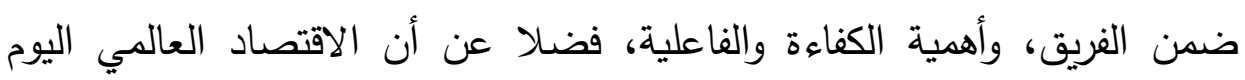

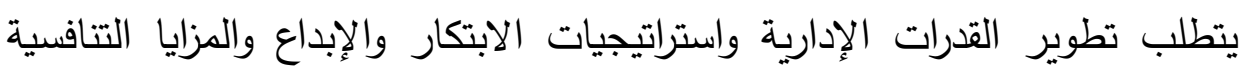
(Meesilapavikkai, 2000, Machadoa et al, 2004, Driscoll, 2010, Kwiek, .(2003, OCED, 2002, Sadlak, 2000, Castells, 2001

ولعل أول من تطرق للتخطيط الاستراتيجي في مجال التعليم العالي هو

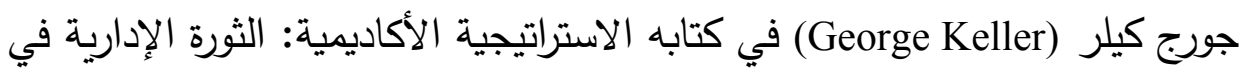

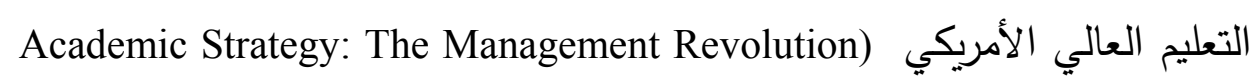
(in American Higher Education الاستراتيجي بأنه عملية نشطة لصنع القرار يتم الاستفادة منها في تحديد هوية 
المؤسسة التعليمية على أفضل وجه ممكن. واقترح بأن يتم تتاول التخطيط الاستراتيجي على نحو جاد وتنفيذه بوصفه الوسيلة التي تؤدي إلى تحسين صورة المؤسسة التعليمية وزيادة حيويتها (الزهراني، 990 (م).

ويناقش رولي وآخرون (Rowely et al., 1997) في كتابهم التغيير

الاستراتيجي في الكليات والجامعات: التخطيط من أجل البقاء والازدهار Strategic Change in Colleges and Universities: Planning to Survive and Prosper ماضي وحاضر المسائل المتعلقة بالتخطيط الاستراتيجي من حيث النظريات والتطبيقات حيث قام الباحثون الثلاثة بتطبيق بعض نظرياتهم في مؤسسات التعليم العالي. وخلص الكتاب إلى أن التعليم العالي سوف يشهذ العديد من التغييرات وأن هذه التغيرات حتمية وأنها ستلامس كافة جوانب التعليم العالي، ومن أجل نجاح هذه التغييرات وبقاء واستمرار المؤسسات لابد من تبني التخطيط الاستراتيجي في كل مؤسسات التعليم العالي سواء على مستوى الكليات أو الجامعات. إن العناصر الضرورية لنجاح التخطيط الاستراتيجي في مجال التعليم هي نفس العناصر التي تعمل على نجاحه في مجال الأعمال، أي العناصر التي تثمل القيادة والمعلومات والأفراد (Manning, 1991). وقد عني بعض الباحثين بدراسة الأطراف المعنية بعملية التخطيط الاستراتيجي في التعليم العالي، فقد أشارت إحدى لإن الدراسات إلى أن (Av) من العاملين في مؤسسات التعليم العالي بأمريكا يمثلون بشكل أو بآخر طرفا في عملية التخطيط الاستراتيجي (Meredith,1993)، في حين أشارت دراسة أخرى إلى أن ثلث العاملين في مؤسسات التعليم العالي كانوا قد فري شاركوا في عمليات تتعلق بالتخطيط الاستراتيجي (Ko Vicki, 1990). كما أشارت دراسة ثالثة إلى أن الجزء الأهم من عملية التخطيط الاستراتيجي يسيطر عليه الإداريون في كل الأوقات وبطرق مختلفة (England-Siegerdt, 2006). 


\section{معوقات التخطيط الاستراتيجي}

يشير هايورد (Hayward, 2008) إلى جملة من التحديات التي تواجه عمليات التخطيط الاستراتيجي للتعليم العالي في عدد من الدول النامية التي عمل فيها، وحدد أبرزها في الإجابة على سؤال "لماذا نخطط"؟ حيث أشار إلى أن منسوبي الجامعات

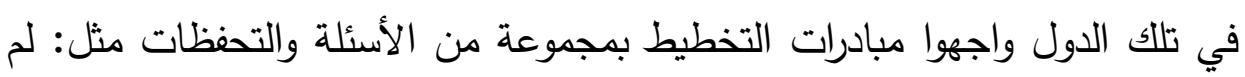
يسبق لنا أن خططنا، فلماذا الآن؟ مشاكلنا كثيرة ولا يجدي معها التخطيط، التخطيط مسؤولية الإدارة العليا، لا جدوى من التخطيط. ويركز الكاتب على أن أحد العقبات الرئيسة هي بدء عملية التخطيط فعليا، وتطرق إلى المعاناة في تشكيل فرق العمل عند إعداد الخطة الاستراتيجية بسبب عزوف العاملين عن العمل فيها، ناهيك عن الافتقار إلى القيادات القادرة على أخذ زمام المبادرة وقيادة العملية التخطيطية والتغييرية. ويؤكد العريني (9 . . rم) أن الكثير من التحديات والتجارب التي أشار إليها (Hayward) تتطبق على الوضع في الجامعات السعودية.

وقد اجته كثير من الباحثين في دراسة الأسباب الحقيقية وراء ضعف كاتف التخطيط الاستراتيجي بالجامعات والمؤسسات التعليمية، حيث يؤكد كاتز وبيكو (Cater and Pucko, 2010) على أن المؤسسات التعليمية إذا أرادت أن تحقق ئق استراتيجياتها فلا بد أن تركز على المتغيرات التنظيمية التي تقف عائقا أمام التخطيط والتتغيذ الاستراتيجي، ويشددا على أن إدارة التغيير عملية هامة من أجل

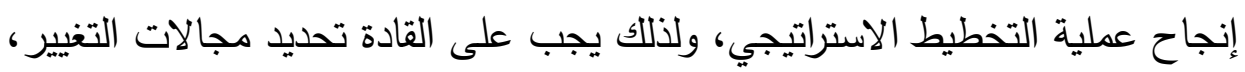
وفي الوقت نفسه تحديد العناصر المقاومة للتغيير والعمل على معالجتها والتغلب عليها. أما هيربينياك (Hrebiniak, 2008) فيرى أن معوقات التخطيط الاستراتيجي الأكثر شيوعا هي تلك المرتبطة بثقافة المنظمة والمتمثلة بانعدام الثقة بين أطراف المنظمة، وهذا يؤدي عادة إلى ضعف أو عدم كفاية تبادل المعلومات والمعارف بين الأفراد أو وحدات الأعمال في المؤسسة. ويتفق هيربينياك (Hrebiniak, 2008) مع وهئ 
جيركوف (Gurkov, 2009) على أن فثل التخطيط الاستراتيجي لا يتأثر بفشل أنش الصياغة الاستراتيجية، بل أنه يتعداها إلى التأثر بفشل تتفيذ الخطة، وعليه فإن فثل

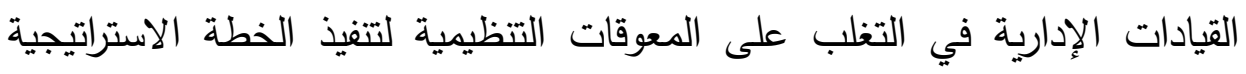
سيؤدي حتما إلى فثل التخطيط الاستراتيجي في المستقبل. أما شولوك وهاريسون (Shulok and Harrison, 1998) فقد أثارا إلى عدة تحديات تواجه التخطيط الاستراتيجي في الجامعات من أبرزها: ضعف التفات القدرة على القي

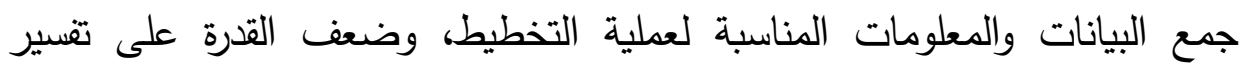
البيانات، فضلا عن ضعف القدرة على استخدام المعلومات في اتخاذ القرارات

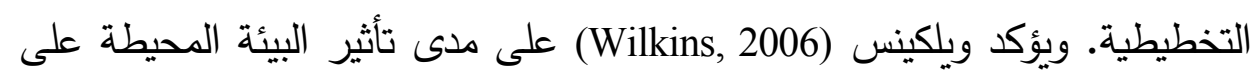
التخطيط الاستراتيجي، وخلص إلى أن هناك عدد من المعوقات البيائية للتخطيط

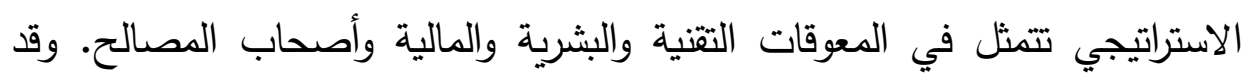
كثف تيو وانج (Teo and Ang, 2001) أن الفشل في الحصول على الفئل دعم الإدارة العليا يعد أكبر مشكلة تواجه التخطيط الاستراتيجي لأنظمة المعلومات، ويشير الإنير إسماعيل وآخرون (Ismail et al., 2007) إلى مجموعة معوقات التخطيط الاستراتيجي في المجال التقني والتكنولوجي في الجامعات الماليزية أبرزها: ضعف التبات التزام الإدارة

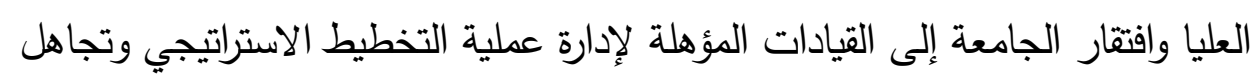
قضايا تتفيذ الخطة الاستراتيجية وعدم وجود دعم مالي كافي لتوطين التكنولوجيا والافتقار إلى الكوادر المدربة في التطوير والتغيير التقني. ولدراسة هذه الظاهرة بشكل أكثر دقة تم تنفيذ عدد من الأبحاث على مستوى منظومة التعليم العالي ببعض الدول، حيث حدد تاجيس (Tagis, 2002) معوقين للتخطيط الاستراتيجي في جامعات (Papua New Guina) هما: ضعف الصفيم لإحلاحيات

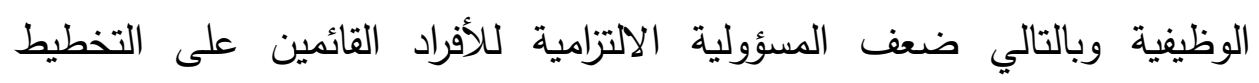


الاستراتيجي وتتفيذه، والمطالب الاجتماعية التقليدية تجاه مؤسسات التعليم العالي ودورها. كما أكد يعقوب وآخرون (Yaakub et al., 2005) على أن افتقار الجامعات إلى المؤسسية الواضحة ذات المعالم والأطر المحددة، هي من العقبات الرئيسة التي تواجه التخطيط الاستراتيجي في الجامعات الماليزية. ووضع ماتثدو وزملاءه (Machadoa, et al., 2004)

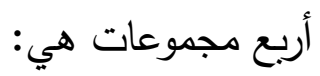

•ضعف توفر الموارد الضرورية: المادية، التكنولوجية، المالية، البشرية. • غياب وضعف الاتصال: كعدم فعالية قنوات الاتصال داخل الحرم الجامعي، وعدم توفر المعلومات الكافية، وعدم إشراك الإدارة العليا في التخطيط، وضعف الحوافز التحفيزية للموظفين. • الصراع والتغيير السريع: ويندرج في إطاره تتامي الصراعات داخل الجامعات، والتغييرات السريعة، وعدم القدرة على صياغة الخطط وتتغيذها. •ضيق الوقت: عدم توفر الوقت الكافي للتخطيط والتنسيق والتكامل بين وحدات الجامعات عند التخطيط.

وكثف شرف وزملاءه (•(1.r) عن مجموعة من معوقات التخطيط الاستراتيجي في مؤسسات التعليم العالي السورية حدّدوها في خمس مجموعات تتمثل مدئ الأولى في المعوقات المتعلقة بطبيعة التخطيط الاستراتيجي مثل غموض المفاهيم المستخدمة في التخطيط الاستراتيجي، وصعوبة استخدام تحليل (SWOT)، وصعوبة توفر قاعدة بيانات تبنى عليها أهداف الخطة. في حين تتعلق المجموعة الثانية من المعوقات بإدارة الجامعة مثل ضعف الاهتمام بالتخطيط، وضعف المتابعة، وعدم المعرفة بالأساليب العلمية التخطيطية، وقلة الخبرة في التخطيط، وانشغال الإدارة بالثؤون اليومية، وجهل الإدارة لخطوات التخطيط الاستراتيجي. أما المجموعة الثالثة 
من المعوقات فقد تعلت بالجامعة والعاملين فيها، مثل ضعف ثقافة التخطيط الاستراتيجي لدى العاملين وانخفاض دافعيتهم للتخطيط، ومقاومة التغيير الاستراتيجي، فضلا عن النظر للتخطيط بأنه نوع من العمل العشوائي المضيع للوقت. في حين تمحورت المجموعة الرابعة حول المعوقات المرتبطة بالإدارة العليا مثل التركيز على النتائج قصيرة المدى، وضعف التحفيز، والتغييرات المستمرة، وعدم تخصيص ميزانية للتخطيط.

وقد وضع بعض الباحثين بعض التصورات الثاملة للمعوقات التي تواجه عملية التخطيط الاستراتيجي بالجامعات، فعلى سبيل المثال، يصنف جونسون (Johnson, 2000) أربعة أنواع هي: تحديات تتعلق بالعنصر البشري (كيف يمكن الحصول على تفاعل العاملين واستجابتهم للتغيرات)، وتحديات تتعلق بالعمليات التخطيطية (كيف يمكن توليد الأفكار الخاصة بالتخطيط بطريقة مبدعة ومبتكرة)، وتحديات تتعلق بالهيكلية (كيف يمكن إدارة الجزء من الكل والتسيق بين خطط الوحدات الفرعية والمركز)، وتحديات تتعلق بالمؤسسة (كيف يمكن إحداث تغييرات في نمط القيادة وثقافة القادة ورؤاهم تتناسب مع متطلبات التخطيط الاستراتيجي).

ويرى ستيفان (Stefan, 2005) أن معوقات التخطيط الاستراتيجي تتمثل في أربعة معوقات رئيسة هي: المعوقات البشرية كمقاومة التغيير والعلاقات الاجتماعية، والمعوقات المالية كالتكلفة العالية للتخطيط الاستراتيجي، والمعوقات المؤسسية كثقافة التعاون والثقة بين أطراف المؤسسة، والمعوقات التقنية كتصميم العمل. وأوجز ميسيلابافيكاي (Meesilapavikkai, 2000) معوقات التخطيط الاستراتيجي Feldman and March, 1981, Rawely et al, 1997, ) كما رآها مجموعة من الباحثين Shulok and Harrison, 1998, Steeples, 1997, Hunt et al., 1997, 
(Schmiditlein, 1995

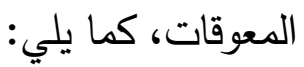

- معوقات تتعلق بالمعلومات: كضعف القدرة على جمع البيانات اللازمة وتفسيرها، وضعف القدرة على تقويم المعلومات وتوفيرها لاتخاذ القرارات التخطيطية على مستوى الوحدات، وغزارة المعلومات، والافتراضات الخاطئة عن مصادر المبادرة في التغيير، والافتراضات غير الصائبة عن نوعية المعلومات المطلوبة للتخطيط. - معوقات إدارية: كالافتقار إلى إدارة عليا لقيادة التخطيط والتغيير، والافتقار للتدريب الإداري لرفع كفاءة ومهارات الإدارين في التخطيط، والافتقار إلى الثقة والانسجام بين العاملين، والتوقعات التي ترى بأن التخطيط سوف يحد من خيارات اتخاذ القرار، والفشل في إيجاد نموذج فعال لعملية التخطيط يوازن بين مطالب المرونة والرقابة، والضغوط والطوارئ، وتعارض مصالح الوحدات الفرعية مع مصلحة المؤسسة الكلية، وديناميكية البيئة المحيطة، وتجنب الحساسية السياسية وبالتالي استبعاد أمور ذات أهمية استراتيجية كبيرة، والافتقار إلى المدافعين عن التغيير في مجال معين.

- معوقات تتعلق بالعمليات التخطيطية: كالحاجة إلى التعامل مع المستقبل دون التضحية بالأشطة الروتينية القائمة، ومشكلات تتفيذ الخطط، والصراعات الأيديولوجية حول مفهوم التخطيط، وارتفاع تكلفة عملية التخطيط، والتوقعات غير الواقعية التي ترى بأن التخطيط سيزيد من الموارد، والفشل في النظر إلى التخطيط كعملية تعلم، وضعف القدرة في الحفاظ على الخطة الاستراتيجية كعملية ذات أثر مستمر . - معوقات خاصة بالحرم الجامعي والعاملين فيه: كصعوبة تهيئة الحرم الجامعي للتغيير، والمعوقات التي يحدثها العاملون حيال المعايير المقترحة، والنظر إلى التخطيط بوصفه غير ملائم للمؤسسة، وغموض المستقبل. 


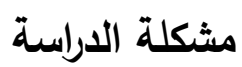

تمثل مؤسسات التعليم العالي حجر الزاوية في تطور المجتمعات ونموها،

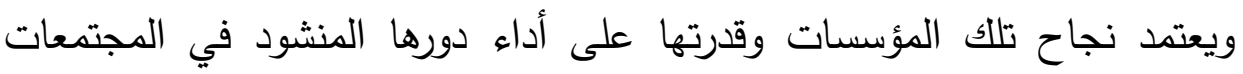

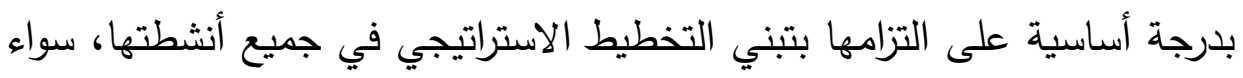

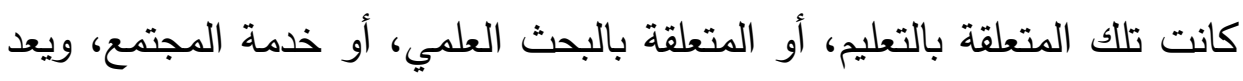

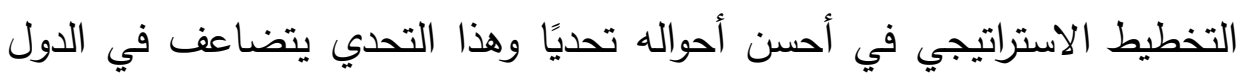
النامية خاصة عندما نتحدث عن التخطيط للتعليم العالي. ومن خلال ملاحظة ومعايشة الباحثين لما يدور في الجامعات السعودية من

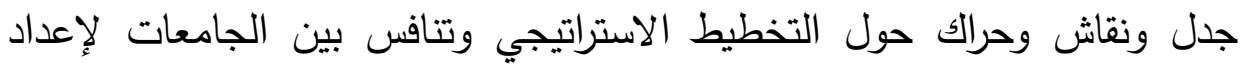

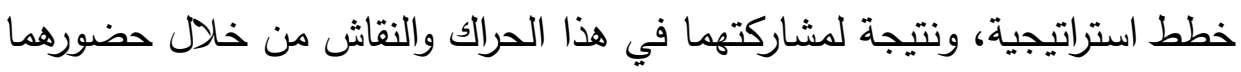
لورش العمل وحلقات النقاش والندوات والدورات والاجتماعات الخاصة بالتخطيط الاستراتيجي في جامعتيهما، فقد اتضح لهما أن هناك معوقات كثيرة في الجامعات ولنات السعودية تقف حائلا دون قيام بعض الجامعات بتطوير خطط استراتيجية تسير وفقها، وإذا وجدت جامعات قد قامت بتطوير خطط استراتيجية فإنها في أحيان

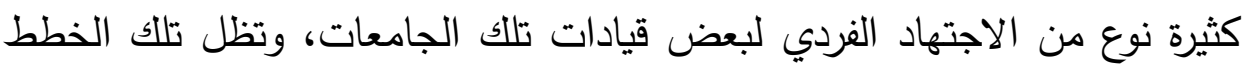

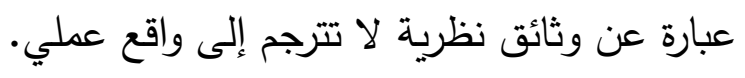
من هنا رأى الباحثان أن يتم دراسة المعوقات التي تحول دون قيام الجامعات

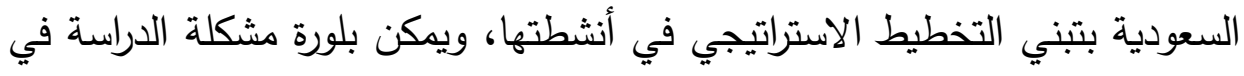

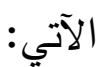
- ما معوقات التخطيط الاستراتيجي في الجامعات السعودية ذات العلاقة

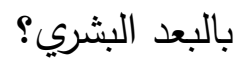


- ما معوقات التخطيط الاستراتيجي في الجامعات السعودية ذات العلاقة بالبعد المالي؟ - ما معوقات التخطيط الاستراتيجي في الجامعات السعودية ذات العلاقة بالبعد الإداري والتظظيمي؟ - ما معوقات التخطيط الاستراتيجي في الجامعات السعودية ذات العلاقة

بعملية التخطيط؟ هل توجد فروق ذات دلالة إحصائية في معوقات التخطيط الاستراتيجي ترجع للمتغيرات الديموغرافية ومتغير الجامعة؟

أهمية الدراسة يعتبر التعرف على معوقات التخطيط الاستراتيجي بالجامعات السعودية مهم جدًا من الناحية العملية حيث أنه سيؤثر إيجابًا على قدرة هذه الجامعات على دئي استخدام أدوات التخطيط الاستراتيجي بالشكل السليم الذي سيسهم في الارتقاء بالعملية الأكاديمية بأبعادها الثلاثة: التعليم والبحث العلمي وخدمة المجتمع. كما لإليطاء تزداد أهمية هذه الدراسة مع توجه الجامعات السعودية للحصول على الاعتمادات الأكاديمية العالمية، إذ أن وجود خطة استراتيجية متكاملة وسليمة يعتبر أحد

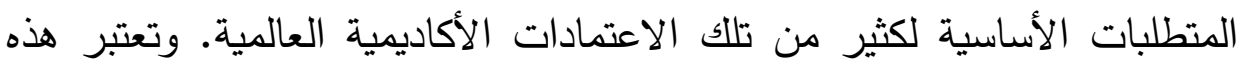
الدراسة في حدود علم الباحثين الدراسة الأولى التي تتناول اتجاهات القيادات الأكاديمية والإدارية بالجامعات السعودية نحو المعوقات التي يمكن أن تؤثر سلبًا على خططها الاستراتيجية. أهداف الاراسة

يسعى الباحثان من خلال إجراء هذا الدراسة إلى تحقيق الأهداف الآتية: - التعرف على واقع التخطيط الاستراتيجي بالجامعات السعودية. - تحديد معوقات التخطيط الاستراتيجي في الجامعات السعودية. 
- التعرف على مدى اختلاف وتباين رؤى القيادات الإدارية العليا والوسطى في الجامعات السعودية إزاء معوقات التخطيط الاستراتيجي تبعا للمتغيرات الديموغرافية.

\section{فرضيات الدراسة}

بناء على الإطار النظري والدراسات السابقة التي تم عرضها فقد تم وضع فرضيات هذه الدراسة على النحو التالي:

الفرضية الأولى: لاتوجد فروق ذات دلالة إحصائية في آراء القيادات الأكاديمية والإدارية في الجامعات السعودية تعزى لمتغير العمر • لمريج.

الفرضية الثانية: لاتوجد فروق ذات دلالة إحصائية في آراء القيادات الأكاديمية والإدارية تعزى لمتغير المنصب الوظيفي.

الفرضية الثالثة: لاتوجد فروق ذات دلالة إحصائية في آراء القيادات الأكاديمية والإدارية تعزى لمتغير الخبرة أو سنوات العمل في الموقع الوظيفي. الفرضية الرابعة: لاتوجد فروق ذات دلالة إحصائية في آراء القيادات الأكاديمية والإدارية في الجامعات السعودية تعزى لمتغير الجامعات.

\section{حدود الاراسة}

تحصر هذه الدراسة في الجامعات السعودية الحكومية التي تم تأسيسها قبل عام · ·. بم، مما لا يسمح لنا بتعميم نتائجها على باقي الجامعات السعودية الحكومية والخاصة. كما أن كون الدراسة تستطلع آراء القيادات الأكاديمية والإدارية بالجامعات محل الدراسة يمنعنا من تعميم النتائج على كافة منسوبي الجامعة وعلى الأخص أعضاء هيئة التدريس. وأخيرًا فإن هذه الدراسة محدودة بالإطار الزمني الذي نفذت خلاله وهو العام الجامعي rr/Tr أهـ 


\section{منهجية الاراسة}

من أجل تحقيق أهداف الدراسة تم استخدام المنهج الوصفي التحليلي، وقد اتبع الباحثان في طريقة العمل عدة مراحل أبرزها:

المرحلة الأولى: مراجعة الأدبيات النظرية والوقوف على معوقات التخطيط الاستراتيجي في الجامعات بصورة دقيقة من خلال الدراسات السابقة التي تمت في هذا الجانب عربيا وعالميا.

المرحلة الثانية: تصميم أداة الدراسة، حيث تم الاستفادة من عدد من

Feldman and March, 1981, Rawely et al., 1997, Shulok and) الدراسات السابقة Harrison, 1998, Steeples, 1997, Hunt et al., 1997, Schmiditlein, 1995, (Meesilapavikkai, 2000 عديدة قسمت على أربعة أبعاد وذللك على النحو التالي: جدول (1). فقرات الاستبيان موزعة وفق الأبعاد.

\begin{tabular}{|c|c|c|}
\hline أرقامها في الاستبيان & عدد الفقرات & البعد البع - ال \\
\hline 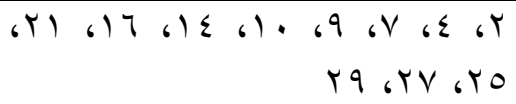 & 11 & المعوقات البشرية. \\
\hline$r T 61161061$ & $\varepsilon$ & المعوقات المالية. \\
\hline 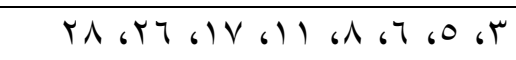 & $\wedge$ & المعوقات الإدارية والتتظيمية. \\
\hline 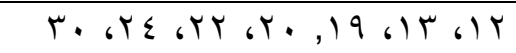 & $\mathrm{V}$ & المعوقات المتعلقة بعملية التخطيط. \\
\hline
\end{tabular}

وبعد تصميم الاستبيان بصورته الأولية تم عرضه على مجموعة من المحكمين لقياس الصدق النظري، ثم تم إخراجه بصورته النهائية بعد إجراء التعديلات التي اقترحها المحكمون.

المرحلة الثالثة: جمع البيانات، حيث تم اختيار الجامعات السعودية المشاركة في الدراسة على أن يكون تاريخ تأسيسها قبل عام . ... بم وذلك لكون عمرها الزمني طويل نسبيًا، إضافة إلى أن لديها خبرة في التخطيط الاستراتيجي من خلال ممارستها له، ومواجتها لمجموعة من العقبات والصعاب خلال مراحل 
تطورها، وقد بلغ عددها (V) جامعات يوضحها الجدول رقم (Y). وقد تم استطلاع آراء القيادات الإدارية والأكاديمية فيها (مديرو جامعات، وكلاء جامعات، جاهي، عمداء

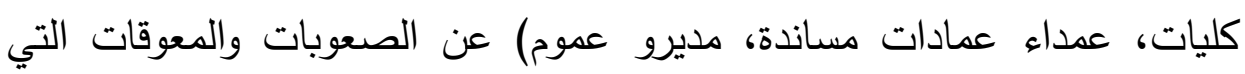
تحول دون إعداد خطط استراتيجية والسير وفقها.

جدول (ץ). المعلومات الخاصة بتوزيع الاستبانة على عينة الدراسة.

\begin{tabular}{|c|c|c|c|c|c|c|c|c|c|}
\hline لالمترجع & الاستترارت & الامتمارت & الإجملي & الإلطيارة & مليرو & المسادات & الكليات & التأسيس & الجامعة \\
\hline$\% 90$ & 07 & 09 & 09 & 9 & 17 & IT & YI & 2) $90 \mathrm{~V}$ & جامعة الملك سعود \\
\hline$\%$ \% & rr & $\varepsilon$. & $\varepsilon$. & $\varepsilon$ & 10 & 11 & $1 \cdot$ & 21971 & الجامعة الإسلامية \\
\hline$\% 1 \ldots$ & rᄉ & r^ & rᄉ & r & 1. & v & $\wedge$ & س797 & جامعة الملك فهز للبترول \\
\hline$\% \mathrm{Vr}$ & $\varepsilon \wedge$ & 77 & 77 & $\wedge$ & 10 & 11 & rr & م) & جامعة الملك عبدالعزيز \\
\hline$\% \vee \wedge$ & $\varepsilon 9$ & 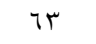 & שד & 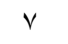 & ir & 1. & $r \leq$ & م) & جامعة أم القرى \\
\hline$\% \wedge 1$ & rq & Tr & r & $\varepsilon$ & 17 & 9 & V & م) & جامعة الإمام محمد \\
\hline$\%$ & $\varepsilon r$ & $\varepsilon r$ & $\varepsilon r$ & $\varepsilon$ & 11 & IT & 17 & م) 910 & جامعة الملك فيصل \\
\hline$\%$. & r10 & reo & reo & rq & 90 & $V Y$ & IrA & & الإجمالي \\
\hline
\end{tabular}

* المعلومات في الجدول مستقاة من المواقع الإكترونية للجامعات على الثبكة العنكبوتية لعام باء؛ اهـ.

المرحلة الرابعة: مرحلة تصنيف البيانات وتحليلها، حيث تم في هذه المرحلة مراجعة الاستمارات وتفريخ البيانات وادراجها في الحاسب الآلي عبر برنامج ومن ثم إجراء اختبار الثبات (الاتساق الداخلي) لفقرات المقياس وأبعاده

من خلال معامل كرومباخ ألفا كما في الجدول رقم (ب). جدول (r). قيمة معامل كرومباخ ألفا للاتساق الداخلي للمقياس.

\begin{tabular}{|c|c|}
\hline قيمة ألفا & الب \\
\hline., 79 & المعوقات البشرية. \\
\hline$\cdot, \wedge$. & المعوقات المالية. \\
\hline$\cdot$ & المعوقات الإدارية والتتظيمية. \\
\hline$\cdot, \wedge 7$ & المعوقات المتعلقة بعملية التخطيط. \\
\hline$\cdot, 9 Y$ & على مستوى الأبعاد جميعًا. \\
\hline
\end{tabular}

الجدول من إعداد الباحثين اعتمادًا على مخرجات التحليل الإحصائي باستخدام الحزمة (SPSS). 
يلاحظ من بيانات الجدول رقم (ب) أن معامل الاتساق الداخلي على مستوى

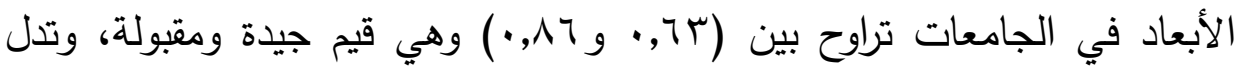
على وجود اتساق داخلي بين فقرات كل بعد، أما على مستوى المقياس ككل فقد بلغ (r9, • ) وهي قيمة مرتفعة تدل على درجة عالية من الاتساق والثبات الداخلي للمقياس.

صفات عينة الاراسة

ا. البيانات الشخصية: - 2 - n

جدول (؛). وصف عينة الدراسة.

\begin{tabular}{|c|c|c|c|}
\hline النسبة \% & التكرار & الفئة & المتغير \\
\hline $1 \ldots$ & rıo & 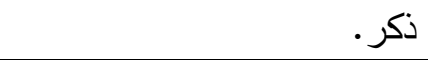 & \multirow{2}{*}{ الجنس. } \\
\hline . & . & أنثى. & \\
\hline $1 \cdot, 9$ & r & من · r إلى أقل من • •ـ سنة. & \multirow{4}{*}{ 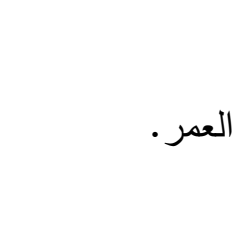 } \\
\hline$\varepsilon 9, \wedge$ & $1 \leqslant r$ & من ·ـ إلى أقل من ·0 سنة. & \\
\hline$r v, 0$ & $1 \cdot v$ & من •0 إلى أقل من . س سنة. & \\
\hline $1, \lambda$ & 0 & . . سنه فأكثر. & \\
\hline$\Lambda, \varepsilon$ & $r \varepsilon$ & إدارة عليا. & \multirow{4}{*}{ الموقع الوظيفي. } \\
\hline$\varepsilon r, 0$ & $1 r \leq$ & عميد كلية. & \\
\hline$r \cdot, V$ & 09 & عميد عمادة مساندة. & \\
\hline$r v, \varepsilon$ & $\vee \wedge$ & مدير عام ومدير مركز . & \\
\hline$r v, q$ & $1 \cdot 1$ & أقل من ع سنوات. & \multirow{4}{*}{ سنوات العمل في } \\
\hline$\varepsilon \wedge, 1$ & 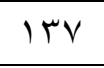 & من ₹ إلى أقل من V سنوات. & \\
\hline $0, r$ & 10 & من V إلى أقل من · ا سنوات. & \\
\hline$\Lambda, \vee$ & ro & • . سنوات فأكثر . & \\
\hline
\end{tabular}

الجدول من إعداد الباحثين اعتمادًا على مخرجات التحليل الإحصائي باستخدام الحزمة (SPSS). 
تبين النتائج الواردة في الجدول رقم (ع) أن القيادات الإدارية في الجامعات جميعهم من الرجال، فهم من يتخذون القرارات، وبرغم وجود شطر للطالبات بمعظم الجامعات المشاركة في الدراسة إلا أن القيادات النسائية بها على مستوى إداري أقل من المستوى الإداري محل الدراسة (أي أقل من عميد أو مدير عام)، وبالتالي فإن مشاركتهن في عملية التخطيط الاستراتيجي هي مشاركة محدودة.

وتشير النتائج إلى أن نحو نصف العينة تتراوح أعمارهم من ( • ؛) إلى أقل من (•0) سنة وهو العمر المنطقي لشغل المناصب القيادية، كما تفصح النتائج

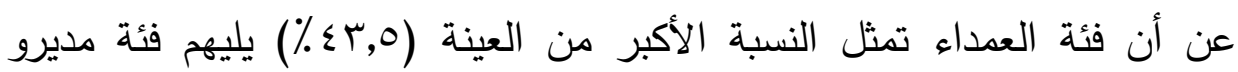

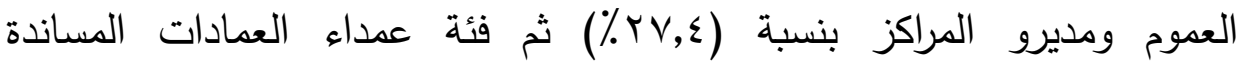

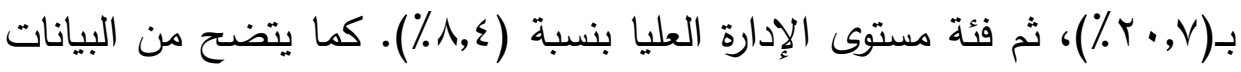

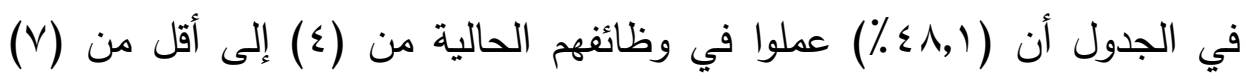
سنوات بينما تتخفض هذه النسبة في الفئة التي تليها (من V إلى أقل من إن سنوات) إلى (؟,0\%)، وهذا يدل على أن المناصب القيادية في الجامعات السعودية تخضع لتغيير قياداتها بشكل دوري. ب. مشاركة العينة وخبرتها في التخطيط الاستراتيجي: 
جدول (•). مشاركة العينة وخبرتها في التخطيط الاستراتيجي.

\begin{tabular}{|c|c|c|c|}
\hline من الجمالية \% & 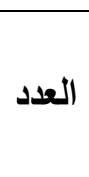 & طبيعة المشاركة & $ت$ \\
\hline 79,0 & 191 & حضور ورش العمل التتقيفية عن التخطيط الاستراتيجي. & 1 \\
\hline or,. & 101 & حضور ورش العمل التخصصية في التخطيط الاستراتيجي. & r \\
\hline$\varepsilon \neg, \vee$ & מזו & اللجامعة. المشاركة في وش العمل الخاصة بوضع الخطة الاستراتيجية & $r$ \\
\hline r৭, & $\Lambda r$ & الاستراتيجية للجامعة. & $\varepsilon$ \\
\hline$r \cdot, q$ & $\wedge \Lambda$ & المشاركة في كتابة وثيقة الخطة الاستراتيجية للجامعة. & 0 \\
\hline$r q, 1$ & $1 \cdot r$ & مراجعة وثيقة الخطة الاستراتيجية للجامعة واقتراح ملاحظات عليها. & 7 \\
\hline rT, & 94 & المشاركة في إقرار الخطة الاستراتيجية للجامعة. & $\mathrm{V}$ \\
\hline rq, & $\Lambda r$ & للجامعة إلى خطط بوش العفيذلة الخاصة بترجمة الخطة الاستراتيجية & $\wedge$ \\
\hline$V T, \cdot$ & $r \cdot \Lambda$ & المشاركة بتنفيذ أجزاء من الخطة الاستراتيجية للجامعة. & 9 \\
\hline$r, Y$ & 19 & المشاركة في مراجعة الخطة الاستراتيجية للجامعة. & 1. \\
\hline $71, \Sigma$ & 1Vo & الإثي تديره. على وضع الخطة الاستراتيجية للقطاع الجامعي & 11 \\
\hline
\end{tabular}

الجدول من إعداد الباحثين اعتمادًا على مخرجات التحليل الإحصائي باستخدام الحزمة (SPSS) (النسبة محتسبة

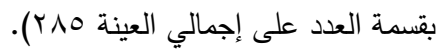

يتبين من النتائج الواردة في الجدول رقم (0) أن ما يقرب من (• •\%) من أفراد العينة حضروا ورش عمل تثقيفية عن التخطيط الاستراتيجي، مما يشير إلى أن هناك اهتمامًا جيدا بنشر ثقافة التخطيط الاستراتيجي في الجامعات السعودية. لكن هذه النسبة تقل عندما يتعلق الأمر بالمشاركة في ورش العمل التخصصية في التخطيط الاستراتيجي (rه\%) أو المشاركة في ورش العمل الخاصة بوضع الخطة

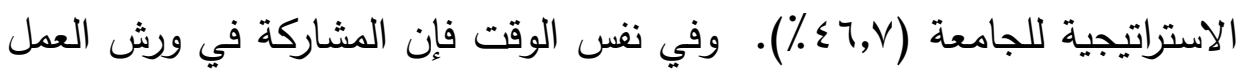
الخاصة بترجمة الخطة الاستراتيجية للجامعة إلى خطط تتفيذية تتخفض إلى 
(9\%). . كذللك الحال بالنسبة للمشاركة في مراجعة الخطة الاستراتيجية للجامعة

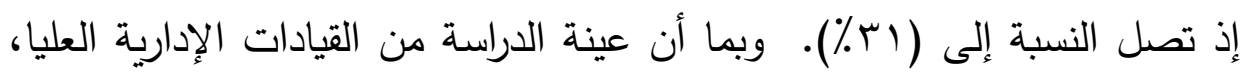
فإن نحو (آ٪\%) من العينة يشرفون على وضع وتتفيذ الخطة الاستراتيجية للقطاع الجامعي الذي يديرونه. مما سبق يتضح أن مشاركة أفراد العينة وخبرتهم في التخطيط الاستراتيجي صياغةً وإقرارًا وتتفيذًا ومراجعةً متدنية إلى حد ما في غالبية محاورها، وهذا لا يرقى إلى كونهم القيادات العليا بالجامعات.

استخلاص أبرز النتائج

تم تحليل نتائج الدراسة وفقا لأربعة أبعاد ضمت معوقات التخطيط الاستراتيجي في الجامعات وهي: المعوقات ذات العلاقة بالبعد البشري، والمعوقات ذات العلاقة بالبعد المالي، والمعوقات ذات العلاقة بالبعد الإداري والتظيمي، والمعوقات ذات العلاقة بعملية التخطيط. وتم الإجابة على أسئلة الدراسة من خلال هذا التحليل كما يأتي:

أولاً: للإجابة على سؤال الدراسة الأول (ما معوقات التخطيط الاستراتيجي في الجامعات السعودية ذات العلاقة بالبعد البشري؟) فقد تم استخراج المتوسطات الحسابية والانحرافات المعيارية لاستجابات أفراد العينة حول معوقات التخطيط الاستراتيجي ذات العلاقة بالبعد البشري. 
جدول (†). المتوسط الحسابي والانحراف المعياري لإجابات أفراد العينة على معوقات التخطيط الاستراتيجي ذات العلاقة بالبعد البشري.

\begin{tabular}{|c|c|c|c|c|c|}
\hline المعتوق & المعياري & الحسابي & العبارة & ت & : \\
\hline متوسط & $1, \varepsilon$. & $r, r$. & نقصط الكوادر الجامعية المتخصصة في & 1 & T \\
\hline متوسط & $1, \Gamma_{1}$ & ץ,T. & 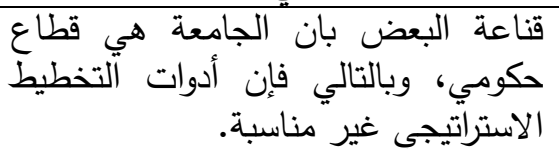 & $r$ & $\varepsilon$ \\
\hline متوسط & $1, r V$ & $r, r$. & 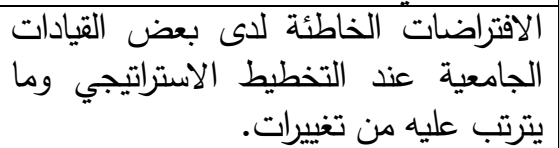 & $r$ & V \\
\hline متوسط & $1, Y \wedge$ & $r, 17$ & 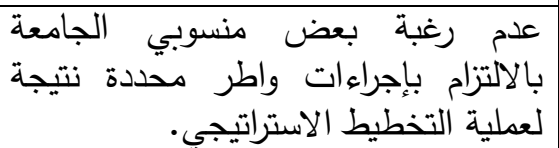 & $\varepsilon$ & 9 \\
\hline متوسط & דז,1, & $r, q 1$ & تتفيذ الخطة الاستراتيجية. الجامعة بإمكانية & 0 & 1. \\
\hline متوسط & $1,1$. & $r, 01$ & 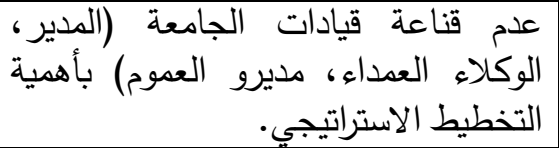 & 7 & $1 \varepsilon$ \\
\hline متوسط & $1, r_{0}$ & $r, 9 r$ & المبادرة وقيادة العملية التخطيطية القادرة على أخذذ زمام & $V$ & 17 \\
\hline منخفض & $1, \cdot r$ & $r, r \varepsilon$ & 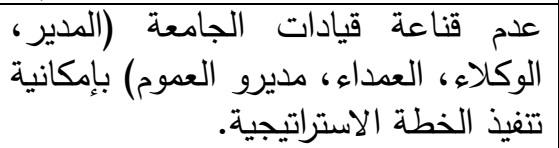 & $\wedge$ & YI \\
\hline متوسط & $1, r V$ & r,T & التخطيط الاستراتيجي. منسوبي الجامعة بأهمية & 9 & ro \\
\hline متوسط & $1, r$. & $r, 1 \leq$ & 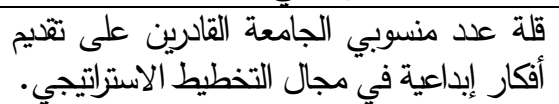 & 1. & TV \\
\hline متوسط & $1, \Gamma \varepsilon$ & $r, \ldots$ & لايناسة البعض طبيعة المؤسسات التخطيط الأكاديمتراتيجي. & 11 & rq \\
\hline متوسط & \multicolumn{2}{|c|}{$r, \wedge V$} & \multicolumn{3}{|l|}{ المتوسط الحسابي المرجح } \\
\hline
\end{tabular}

الجدول من إعداد الباحثين اعتمادًا على مخرجات التحليل الإحصائي باستخدام الحزمة (SPSS). 
يلاحظ من النتائج الواردة في الجدول رقم (7) والمتعلقة بإجابات أفراد العينة على فقرات البعد البشري أن "نقص الكوادر الجامعية المتخصصة في التخطيط الاستراتيجي" و "الافتراضات الخاطئة لدى بعض القيادات الجامعية عن التخطيط الاستراتيجي وما يترتب عليها من تغييرات" جاءا في مقدمة عوائق التخطيط

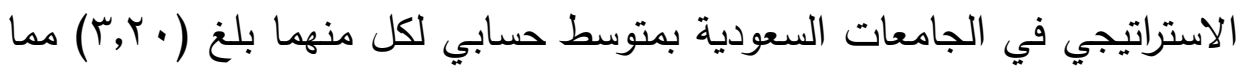
يعني أنهما معوقان بدرجة متوسطة، وجاء بالمرتبة الثانية من حيث ترتيب العوائق ذللك المتعلق بـ "عدم رغبة بعض منسوبي الجامعة بالالتزام بإجراءات وأطر محددة نتيجة لعملية التخطيط الاستراتيجي" بمتوسط حسابي (؟ ا,ץ)، تلاه في الترتيب المعوق المتمثل بـ "قلة عدد منسوبي الجامعة القادرين على تقديم أفكار إبداعية في مجال التخطيط الاستراتيجي" بوسط حسابي قدره (ع ا,ץ). لكن عندما يتعلق الأمر بـ "عدم قناعة قيادات الجامعة (المدير ، الوكلاء، العدداء، مديرو العموم) بإمكانية

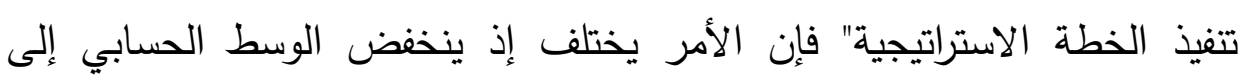
(؟Y,r, وهي قيمة تجعلنا نستبعد هذا المتغير من معوقات التخطيط الاستراتيجي في الجامعات السعودية. وبصورة عامة فقد بلغ الوسط الحسابي المرجح لفقرات هذا البعد (r,AV) وهي قيمة تقع في المدى المتوسط.

ثانيًا: للإجابة على سؤال الدراسة الثاني (ما معوقات التخطيط الاستراتيجي في الجامعات السعودية ذات العلاقة بالبعد المالي؟) فقد تم استخراج المتوسطات الحسابية والانحرافات المعيارية لاستجابات أفراد العينة حول معوقات التخطيط الاستراتيجي ذات العلاقة بالبعد المالي. 
جدول (V). المتوسط الحسابي والانحراف المعياري لإجابات أفراد العينة على معوقات التخطيط الاستراتيجي ذات العلاقة بالبعد المالي.

\begin{tabular}{|c|c|c|c|c|c|}
\hline 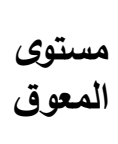 & المعياري & الحستبطي & العبارة & ت & 胥. \\
\hline متوسط & אT, & Y,V & 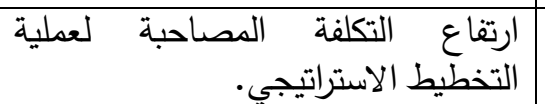 & 1 & 1 \\
\hline متوسط & $1,1 \pi$ & $r, \cdot r$ & والنظمة وإجراءات إقرار ميزانية الجامعة & $r$ & 10 \\
\hline متوسط & 1,01 & r,9 & الاستراتيجية. & $r$ & 11 \\
\hline منخفض & $1,1 Y$ & $r, r V$ & شح اللازمة لعملية التخطيط الآستراتيجي. بالجامعة & $\varepsilon$ & r \\
\hline متوسط & \multicolumn{2}{|c|}{$r, V \wedge$} & \multicolumn{3}{|l|}{ المتوسط الحسابي المرجح } \\
\hline
\end{tabular}

الجدول من إعداد الباحثين اعتمادًا على مخرجات التحليل الإحصائي باستخدام الحزمة (SPSS).

أفصحت النتائج من خلال الجدول رقم (V) المتعلق بالبعد المالي أن قيم المتوسطات الحسابية لإجابات أفراد العينة على متغيرات هذا البعد تراوحت بين (r,rV) الجامعة والصرف من بنودها" أكثر المعوقات من وجهة نظر أفراد العينة إذ بلغ المتوسط الحسابي لهذا المعوق (r.,r)، وهي قيمة متوسطة، فيما يرى أفراد العينة

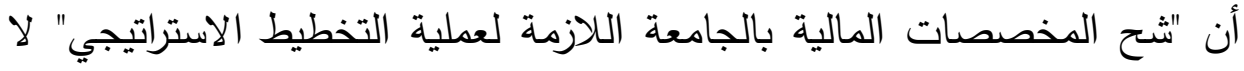
يمثل معوقا من معوقات التخطيط الاستراتيجي، إذ بلغت قيمة الوسط الحسابي وهي قيمة منخفضة تدل على التأثير الضعيف لهذا المعوق. وبصورة (Y,rV) عامة بلغ المتوسط الحسابي المرجح لهذا البعد (Y,VA) وهي قيمة متوسطة. ثالثًا: للإجابة على سؤال الدراسة الثالث (ما معوقات التخطيط الاستراتيجي في الجامعات السعودية ذات العلاقة بالبعد الإداري والتنظيمي؟) فقد تم استخراج 
المتوسطات الحسابية والانحرافات المعيارية لاستجابات أفراد العينة حول معوقات التخطيط الاستراتيجي ذات العلاقة بالبعد الإداري والتتظيمي. جدول (^). المتوسط الحسابي والانحراف المعياري لإجابات أفراد العينة على معوقات التخطيط الاستراتيجي ذات العلاقة بالبعد الإداري والتنظيمي.

\begin{tabular}{|c|c|c|c|c|c|}
\hline مستوى - المعوق & الانحراف & المتوسط & العبارة & ت & 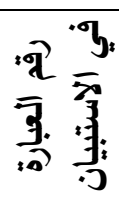 \\
\hline متوسط & $1, Y V$ & $r, r$. & ضنسف فعالية وسائل الاتصال مع & 1 & $\mu$ \\
\hline متوسط & •. & r,1 & في والتتافس فيما المصالح الخاصة بالكليات واحدة. & $r$ & 0 \\
\hline متوسط & $1, \leqslant 9$ & r,qА & في الجامعة ثقافة التخطيط الاستراتيجي & $r$ & 7 \\
\hline متوسط & $1,1 \wedge$ & $r, T r$ & 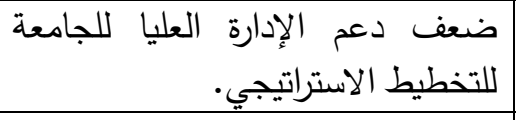 & $\varepsilon$ & $\Lambda$ \\
\hline متوسط & $1,1 \wedge$ & $Y, T \leq$ & 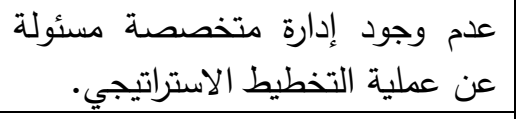 & 0 & 11 \\
\hline متوسط & $1, \Gamma$. & ع ., r & 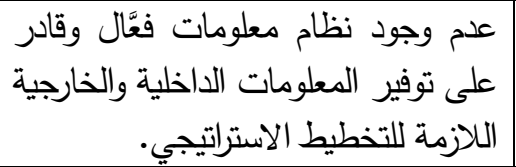 & 7 & IV \\
\hline متوسط & $1, \cdot 1$ & $r, . q$ & عدم الالتزام بتنفيذ الخطة الاستراتيجية & V & YT \\
\hline متوسط & هץ, & $r, r q$ & 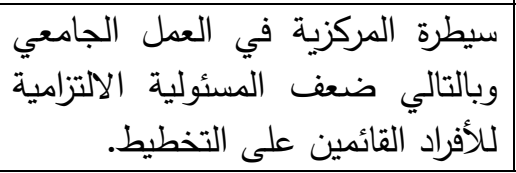 & $\Lambda$ & rᄉ \\
\hline متوسط & \multicolumn{2}{|c|}{ r,... } & \multicolumn{3}{|l|}{ الوسط الحسابي المرجح } \\
\hline
\end{tabular}

الجدول من إعداد الباحثين اعتمادًا على مخرجات التحليل الإحصائي باستخدام الحزمة (SPSS). 
أبرزت نتائج الجدول رقم (^) أن "سيطرة المركزية في العمل الجامعي

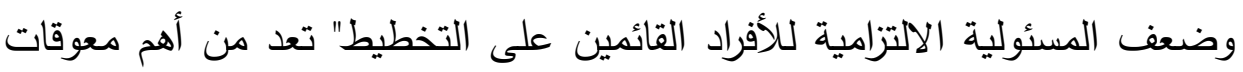

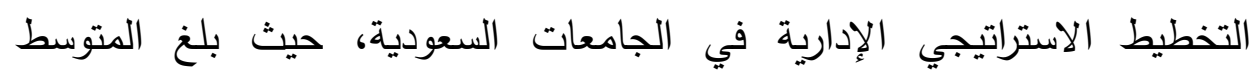

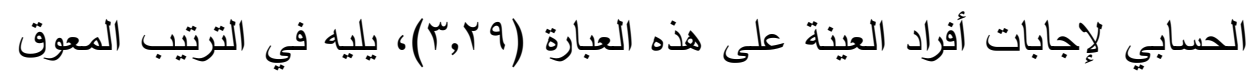

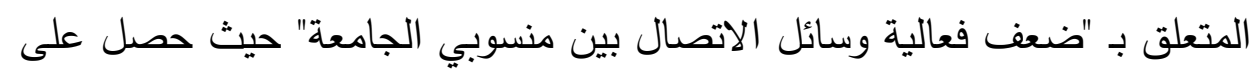

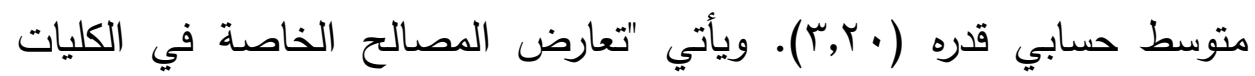

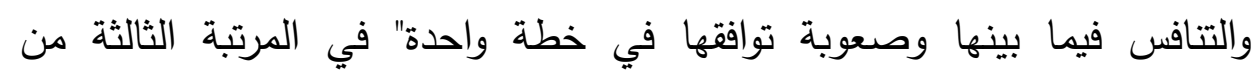

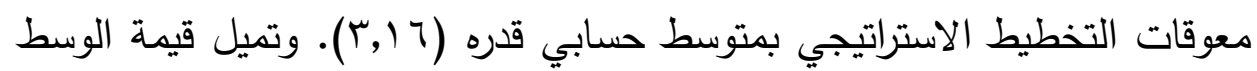

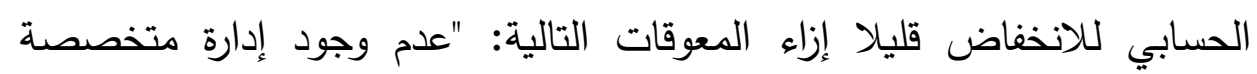

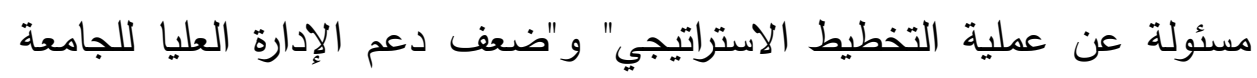

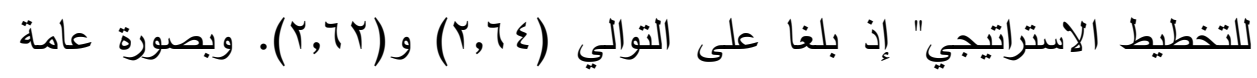
يتضح أن جميع المتغيرات في هذا البعد مثلت معوقات للتخطيط الاستراتيجي في الجامعات السعودية وإن تفاوتت الآراء حولها، وقد بلغ المتوسط الحسب الحسابي المرجح لفقرات هذا البعد (·, (ץ) وهي قيمة متوسطة. رابعًا: للإجابة على سؤال الدراسة الرابع (ما معوقات التخطيط الاستراتيجي

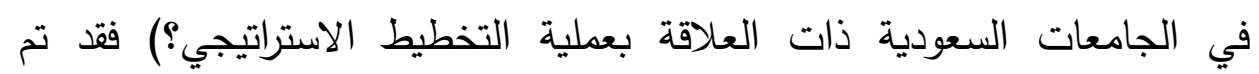

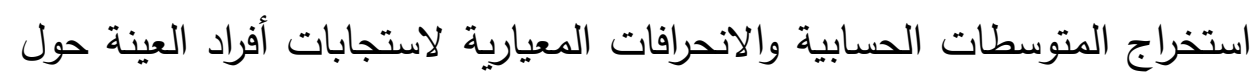
معوقات التخطيط الاستراتيجي ذات العلاقة بعملية التخطيط الاستراتيجي. 
جدول (9). المتوسط الحسابي والانحراف المعياري لإجابات أفراد العينة على معوقات التخطيط الاستراتيجي ذات العلاقة بعملية التخطيط.

\begin{tabular}{|c|c|c|c|c|c|}
\hline المعوق & 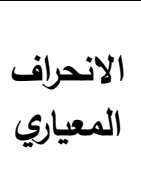 & المستوسط & العبارة & $ت$ & 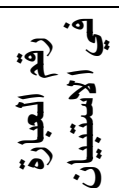 \\
\hline متوسط & $1,1 \leq$ & $r, \cdot \Sigma$ & وقتا طويلا. & 1 & IT \\
\hline متوسط & 1,19 & $r, \wedge$. & 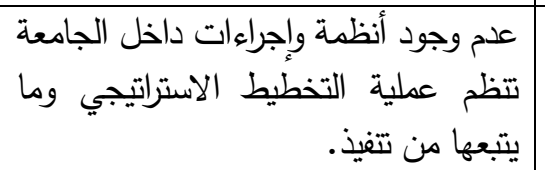 & $r$ & $\pi$ \\
\hline متوسط & 1,11 & r,.. & 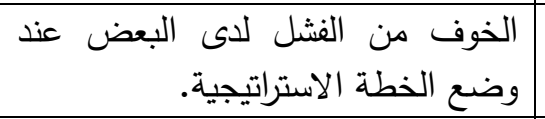 & $r$ & 19 \\
\hline متوسط & $1,1 r$ & r,Tr & 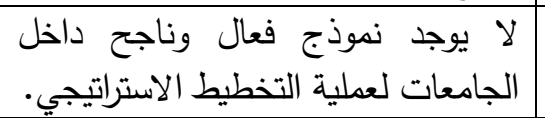 & $\varepsilon$ & $r$. \\
\hline متوسط & 1,17 & $r, \vee \top$ & 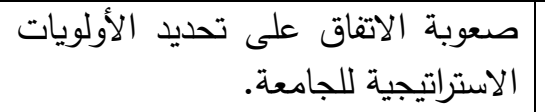 & 0 & Tr \\
\hline متوسط & $1, Y 7$ & $r, 79$ & وتعقيداتها. & 7 & $r \varepsilon$ \\
\hline متوسط & $1, \pi q$ & $r, 09$ & وأهداف الجامعة الاتفاق على تحديد غايات & $V$ & r. \\
\hline متوسط & \multicolumn{2}{|c|}{$r, v q$} & \multicolumn{3}{|l|}{ المتوسط الحسابي المرجح } \\
\hline
\end{tabular}

الجدول من إعداد الباحثين اعتمادًا على مخرجات التحليل الإحصائي باستخدام الحزمة (SPSS).

يتضح من خلال نتائج التحليل الإحصائي المبينة في الجدول رقم (9) أن طول الوقت الذي تستغرقه عملية التخطيط الاستراتيجي يعد معوقًا أساسيا من معوقات التخطيط في الجامعات السعودية، وقد تصدر المعوقات المتعلقة بعملية التخطيط نفسها بمتوسط حسابي (ع +,r)، وعلى ما يبدو فإن عملية التحليل البيئي الداخلي والخارجي بطبيعتها تتطلب وقتا كبيرا إضافة إلى الوقت الذي تتطلبه عملية 
وضع الرؤية والرسالة والأهداف ومراجعتها ومن ثم وضع الخطط التفصيلية والموازنات التقديرية وغيرها من مراحل عملية التخطيط، الأمر الذي يدفع بالكثير من قادة الجامعات ومؤسسات التعليم العالي إلى العزوف عن تبني التخطيط الاستراتيجي. كما ترى القيادات الجامعية أن "الخوف من الفشل لدى البعض عند

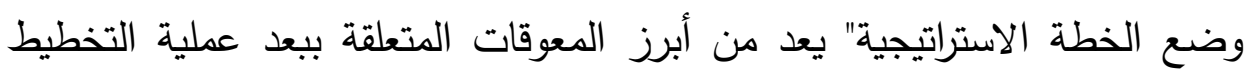

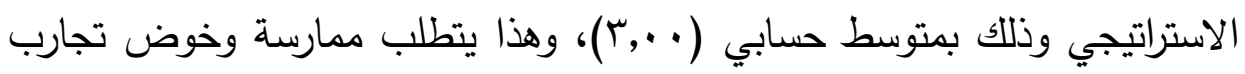
عديدة في إعداد الخطط وتتفيذها حتى يتم التخلص من هذا الخوف.

ويبدو أن "عدم وجود أنظمة وإجراءات داخل الجامعة تتظم عملية التخطيط

الاستراتيجي وما يتبعها من تنفيذ" تشكل عائقا أمام التخطيط الاستراتيجي في

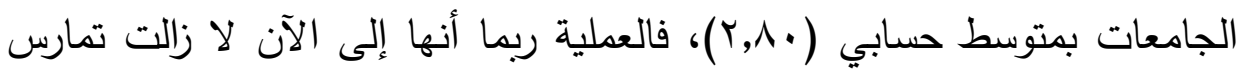
في الكثير من الجامعات بدون لوائح وأنظمة وإجراءات تتظمها، مما يجعلها في وجهة نظر الكثيرين عملية عشوائية تغلب عليها الاجتهادات الشخصية، كما يراها البعض عملية يعتريها الكثير من الصعوبة والتعقيد وبالتالي تمثل هذه الصعوبة والتعقيد عائقا وحائلا أمام القيام بإعداد خطط استراتيجية. ومما يزيد الأمر صعوبة وتعقيدا هو "عدم وجود نموذج فعال وناجح داخل الجامعات لعملية التخطيط الاستراتيجي" (بمتوسط حسابي يبلغ بآ, ) فقد زاد ذلك من غموض الرؤيا وضبابية المشهد لاى قيادات الجامعات. وعموما فإن هذا البعد بمتغيراته المتعددة يعد من المعوقات الرئيسة للتخطيط الاستراتيجي كون متغيراته تتعلق بعملية

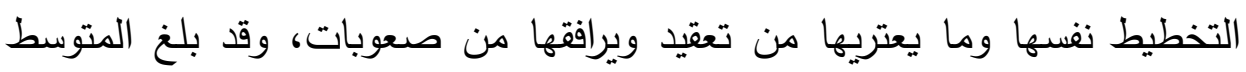
الحسابي المرجح لجميع متغيرات هذا البعد (Y,V9) وهي قيمة متوسطة. من خلال ما طرح سابقا يتضح أن معوقات التخطيط الاستراتيجي في الجامعات السعودية تتراوح قيم متوسطاتها الحسابية بين أعلى قيمة (وب,r) وأدنى قيمة (ع ب,r). ويمكن إبراز أهم سبعة معوقات مرتبة حسب قيم الوسط الحسابي 
ا. سيطرة المركزية في العمل الجامعي وبالتالي ضعف المسئولية الالتزامية للأفراد القائمين على التخطيط.

r. نقص الكوادر الجامعية المتخصصة في التخطيط الاستراتيجي. r. الافتراضات الخاطئة لدى بعض القيادات الجامعية عند التخطيط الاستراتيجي وما يترتب عليه من تغييرات.

ع. ضعف فعالية وسائل الاتصال مع منسوبي الجامعة.

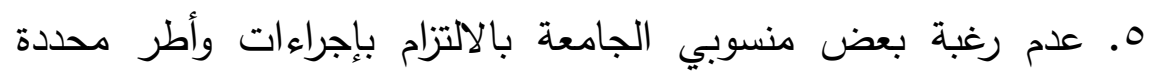
نتيجة لعملية التخطيط الاستراتيجي. T. تعارض المصالح الخاصة بالكليات والتنافس فيما بينها وصعوبة توافقها في خطة واحدة.

V. قلة عدد منسوبي الجامعة القادرين على تقديم أفكار إبداعية في مجال التخطيط الاستراتيجي.

في حين ظهر متغيران حصلا على قيم متوسطات حسابية تقل عن (r,0. (ب)

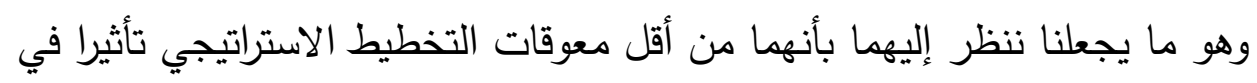
الجامعات السعودية حسب وجهة نظر القيادات الإدارية في الجامعات محل

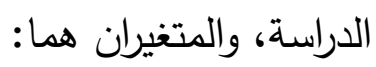

1. عدم قناعة قيادات الجامعة (المدير ، الوكلاء، العداء، مديرو العوم)

بإمكانية تتفيذ الخطة الاستراتيجية.

r. شح المخصصات المالية بالجامعة اللازمة لعملية التخطيط الاستراتيجي. 
خامسًا: للإجابة على سؤال الدراسة الخامس (هل توجد فروق ذات دلالة إحصائية في معوقات التخطيط الاستراتيجي ترجع للمتغيرات الديموغرافية ومتغير الجامعة؟) فقد تم اختبار أربع فرضيات وكانت النتائج كما يأتي: نتيجة اختبار الفرضية الأولى

تتص الفرضية على عدم وجود فروق ذات دلالة إحصائية في آراء القيادات الأكاديمية والإدارية في الجامعات السعودية تعزى لمتغير العمر. ولاختبار هذه الفرضية تم إجراء تحليل التباين (One-Way ANOVA) الظاهرة نتائجه في

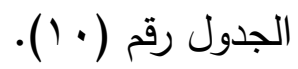

جدول (· (1). نتائج اختبار (One-Way ANOVA) لمعرفة معنوية الفروق بين آراء أفراد العينة تبعا لمتغير العمر.

\begin{tabular}{|c|c|c|c|c|c|c|c|c|}
\hline الدالاة & قيمة & متوسط & لدرجة & المجموع & مصدر التباين & المتوسط & $\mathbf{N}$ & العمر \\
\hline \multirow{4}{*}{,,+} & \multirow{4}{*}{7,0} & \multirow{4}{*}{$\begin{array}{l}r \quad \leqslant 0,9 \\
\varepsilon \cdot v, \cdot 9\end{array}$} & \multirow{4}{*}{$\begin{array}{l}r \\
r \wedge 1 \\
r \wedge \varepsilon\end{array}$} & \multirow{4}{*}{$\begin{array}{l}\text { VqrV,V } \\
\text { U I rqr, } \\
\text { Irrrr., 11 }\end{array}$} & \multirow{4}{*}{ خارج المجموعات المجموعات } & $9 \cdot, 01$ & M & • r إلى أقل من ·ع \\
\hline & & & & & & 10,9 & $1 \leqslant r$ & •ـ إلى أقل من .0 \\
\hline & & & & & & $V \wedge, T V$ & $1 \cdot V$ & • 1 إلى أقل من . \\
\hline & & & & & & $07, \varepsilon$ & 0 & • 7 سنه فأكثر \\
\hline
\end{tabular}

الجدول من إعداد الباحثين اعتمادًا على مخرجات التحليل الإحصائي باستخدام الحزمة (SPSS).

يتضح من خلال النتائج وجود فروق معنوية ذات دلالة إحصائية في إجابات أفراد العينة حول معوقات التخطيط الاستراتيجي تبعا لمتغير العمر، وتبين النتائج أن التباين كان لصالح الفئة العدرية (من · ب إلى أقل من • ع) سنة حيث

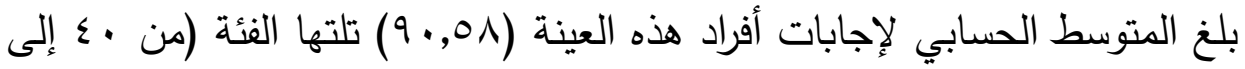
أقل من •0) سنة بمتوسط حسابي (^0,9) مما يؤكد على أن الفئات العمرية الأدنى أكثر إدراكا لمعوقات التخطيط الاستراتيجي من الفئات العمرية الأعلى، وربما يرجع ذلك إلى نشاط وحيوية وأداء الفئات العمرية الأقل. وعليه يتقرر رفض مله فرضية العدم والقبول بالفرضية البديلة. 


\section{نتيجة اختبار الفرضية الثانية}

وتتص على عدم وجود فروق ذات دلالة إحصائية في آراء القيادات

الأكاديمية والإدارية تعزى لمتغير المنصب الوظيفي. ولاختبار هذه الفرضية تم إجراء تحليل التباين (One-Way ANOVA) الظاهرة نتائجه في الجدول رقم (1). جدول (11). نتائج اختبار (One-Way ANOVA) لمعرفة معنوية الفروق بين آراء أفراد العينة تبعا لمتغير المنصب الوظيفي.

\begin{tabular}{|c|c|c|c|c|c|c|c|c|}
\hline قالدالة & قيمة & متوسط & الحرية & المربعات & مصدر التباين & المتوسط & $\mathbf{N}$ & الوظيفي \\
\hline \multirow[t]{4}{*}{$\cdot, \cdot Y_{1}$} & \multirow[t]{4}{*}{$r, r$} & \multirow{4}{*}{$\begin{array}{l}\text { IrNo } \\
\varepsilon r \cdot, 0\end{array}$} & \multirow{4}{*}{$\begin{array}{c}r \\
r \wedge l \\
r \wedge \varepsilon\end{array}$} & \multirow{4}{*}{$\begin{array}{l}\sum 100 \\
\text { IINIVO,Y } \\
\text { IYTM.,Y }\end{array}$} & \multirow{4}{*}{ خارج المجموعات المجموعات } & $v r, \cdot \varepsilon$ & $r \leq$ & إدارة عليا \\
\hline & & & & & & $\Lambda 1, . r$ & ITE & عميد كلية \\
\hline & & & & & & $\wedge \uparrow, 0$ & 09 & عميد عمادة مسانده \\
\hline & & & & & & $\wedge 0, \mathrm{~V}$ & $\vee \wedge$ & مدير عام \\
\hline
\end{tabular}

الجدول من إعداد الباحثين اعتمادًا على مخرجات التحليل الإحصائي باستخدام الحزمة (SPSS).

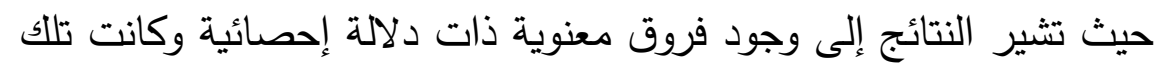

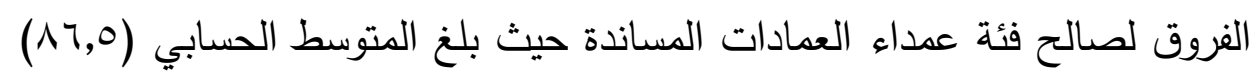

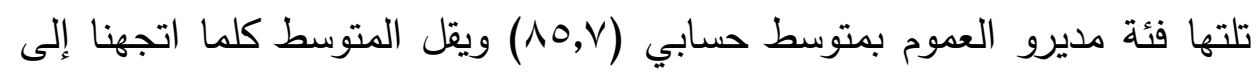

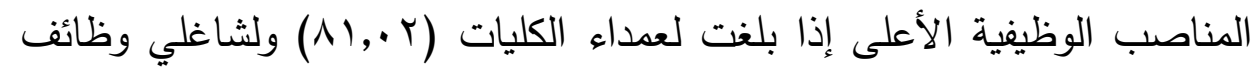

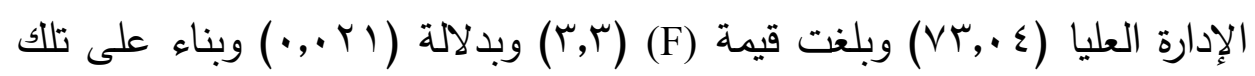
النتائج يتم رفض فرضية العدم المنصوص عليها سابقا والقبول بالفرضية البديلة التي تص على وجود فروق معنوية ذات دلالة إحصائية في آراء القيادات الأكاديمية تعزى لمتغير المنصب وجود الوظيفي. معنوية ذات 


\section{نتيجة اختبار الفرضية الثالثة}

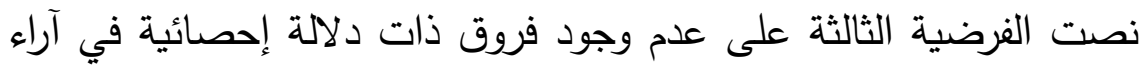

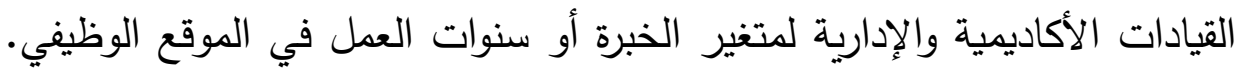
ولاختبار هذه الفرضية تم إجراء تحليل التباين (One-Way ANOVA) الظاهرة نتائجه في الجدول رقم (r ( ).). جدول (ז'). نتائج اختبار (One-Way ANOVA) لمعرفة معنوية الفروق بين آراء أفراد

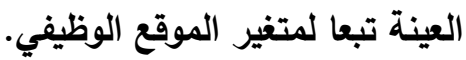

\begin{tabular}{|c|c|c|c|c|c|c|c|c|}
\hline قالدالة & قيمة & متوسط & الحرية & المربعات & مصدر التباين & المتوسط & $\mathbf{N}$ & سنوات العمل في \\
\hline \multirow[t]{4}{*}{$\cdot, \cdots$} & \multirow[t]{4}{*}{$V, 7$} & \multirow{4}{*}{$\begin{array}{l}r \cdot \Sigma r, T \\
\Sigma \cdot r, q\end{array}$} & \multirow{4}{*}{$\begin{array}{l}r \\
r \wedge 1 \\
r \wedge \varepsilon\end{array}$} & \multirow{4}{*}{ 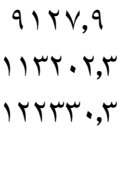 } & \multirow{4}{*}{ 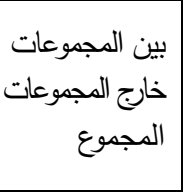 } & $V 7,9$ & $1 \cdot 1$ & اقل من س سنوات \\
\hline & & & & & & $\Lambda \varepsilon, r$ & ITN & צ-7 سنوات \\
\hline & & & & & & 94,7 & 10 & V-9 سنوات V-9 \\
\hline & & & & & & $9 \leqslant, 0$ & $r \varepsilon$ & • ا سنوات فأكثر \\
\hline
\end{tabular}

الجدول من إعداد الباحثين اعتمادًا على مخرجات التحليل الإحصائي باستخدام الحزمة (SPSS).

وخلصت نتائج التحليل إلى وجود فروق ذات دلالة إحصائية عند مستوى الته

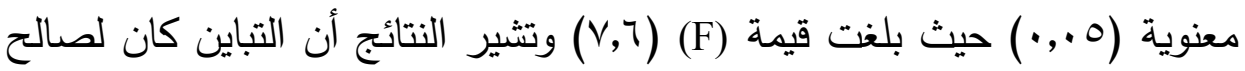

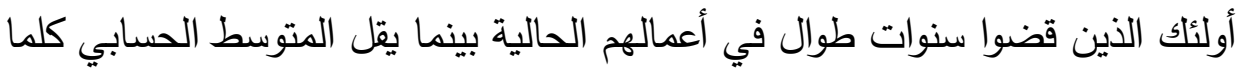

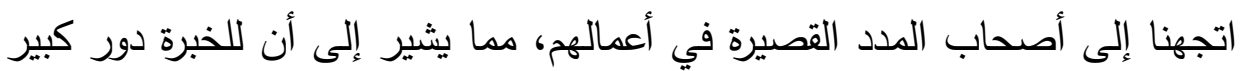

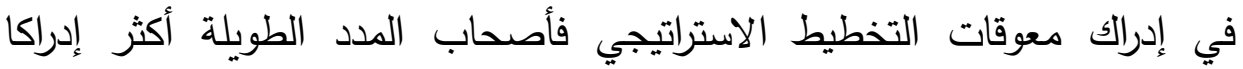

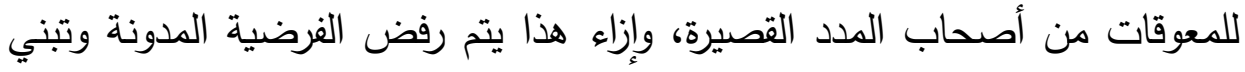
الفرضية البديلة التي تتص على وجود تلك الفروق.

\section{نتيجة اختبار الفرضية الرابعة}

وتتص على عدم وجود فروق ذات دلالة إحصائية في آراء القيادات الأكاديمية

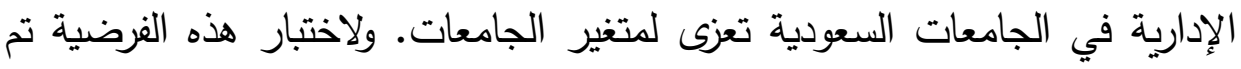
إجراء تحليل التباين (One-Way ANOVA) الظاهرة نتائجه في الجدول رقم (ب (1). 
جدول (r) I I). نتائج اختبار (One-Way ANOVA) لمعرفة معنوية الفروق بين آراء أفراد العينة تبعا لمتغير الجامعات.

\begin{tabular}{|c|c|c|c|c|c|c|c|c|}
\hline قالدالة & قيمة & متوسط & الحربة & المربعات & مصدر التباين & المتوسط & $\mathbf{N}$ & الجامعة \\
\hline \multirow[t]{7}{*}{$\cdot, \cdots$} & \multirow[t]{7}{*}{$v 0,9$} & \multirow{7}{*}{$\begin{array}{l}1 \text { r7ov,r } \\
177,9\end{array}$} & \multirow{7}{*}{$\begin{array}{c} \\
\text { TVA } \\
\text { rAE }\end{array}$} & \multirow{7}{*}{ 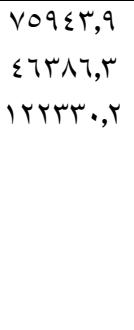 } & \multirow{7}{*}{ خارج المجموعات المجموعات } & $9 \wedge, \wedge$ & $\varepsilon \wedge$ & الجامعة رقم (1) \\
\hline & & & & & & I.r,V & $\leqslant 9$ & الجامعة رقم (Y) \\
\hline & & & & & & $1.7,0$ & rT & الجامعة رقم (r) \\
\hline & & & & & & $7 \varepsilon, 1$ & 07 & الجامعة رقم (ع) \\
\hline & & & & & & $9 r, \wedge$ & $\varepsilon r$ & الجامعة رقم (0) \\
\hline & & & & & & $71, r$ & rq & الجامعة رقم (؟) \\
\hline & & & & & & $V V, 1$ & rᄉ & الجامعة رقم (V) \\
\hline
\end{tabular}

الجدول من إعداد الباحثين اعتمادًا على مخرجات التحليل الإحصائي باستخدام الحزمة (SPSS).

وقد تبين من خلال النتائج الواردة أن هناك فروق معنوية ذات دلالة إحصائية في آراء القيادات الجامعية السعودية تبعا لمتغير الجامعات، فآراء القيادات تتباين من جامعة لأخرى، وقد بلغت قيمة (F) المحسوبة (V0,9) عند مستوى الدلالة (·, •.) وهذا يقتضي رفض الفرضية العدمية والقبول بالفرضية البديلة.

وبالنظر إلى كل جامعة على حدة نجد أن هناك اختلافا بين الجامعات في قيم المتوسطات الحسابية للمعوقات وفي ترتيب المعوقات حسب درجة الموافقة عليها كما هو واضتح في الجدول رقم (ع (). 
جدول (؛ 1). المتوسطات الحسابية لإجابات أفراد العينة على كل فقرة وعلى مستوى كل جامعة والمتوسط الحسابي المرجح لكل الجامعات.

\begin{tabular}{|c|c|c|c|c|c|c|c|c|}
\hline الصسابي العام & رقم (V) & رقم (؟) الجامعة & رقم (•) & رقم (ع الجعة & رقم (r) & رقم (r) & رقم (1) & المتغير \\
\hline$r, r$. & $r, \ldots$ & 1,10 & r,Tr & 1,10 & $\varepsilon, r_{0}$ & $\varepsilon, r_{0}$ & $\varepsilon, r_{0}$ & $\mathrm{X} 2$ \\
\hline$r, T$. & $1, V r$ & $r, r T$ & $r, 91$ & $r, Y \wedge$ & $r, .7$ & $r, \wedge V$ & $r, \cdot r$ & $\mathrm{X} 4$ \\
\hline$r, Y$. & r.rT & r, o & $r, \varepsilon \varepsilon$ & r,Tr & T,q & $r, 90$ & r,Vo & X7 \\
\hline$r, 17$ & $r, \wedge \wedge$ & $1, \wedge 1$ & $r, r r$ & $r, 1$. & $\varepsilon, \ldots$ & $\varepsilon, 9$ & r,q. & X9 \\
\hline$r, q 1$ & $1, \wedge 7$ & $r, \cdot \Lambda$ & $r, \Sigma Y$ & $r, 1$. & $r, V I$ & $r, 1 T$ & $\varepsilon, 0$ & $\mathrm{X} 10$ \\
\hline$r, 01$ & $1,7 \pi$ & $r, 19$ & Y,TT & $r, \ldots$ & $r, V T$ & $r, \wedge V$ & $r, \varepsilon \wedge$ & X14 \\
\hline r,qY & $r, \cdot T$ & $1, V r$ & $r, I T$ & $1,9 V$ & $\varepsilon, 1 T$ & $r, \wedge V$ & $r, 0 \wedge$ & $\mathrm{X} 16$ \\
\hline$r, r \leq$ & $1, \wedge 0$ & $r, \ldots$ & $r, V T$ & $1,7 \mathrm{~V}$ & $r, \cdot T$ & $r, V \varepsilon$ & $r, r$. & $\mathrm{X} 21$ \\
\hline r,Tr & $1, \wedge r$ & $1,0$. & $r, 1 \leq$ & 1,71 & r, & $r, \vee \varepsilon$ & $r, r$. & $\mathrm{X} 25$ \\
\hline$r, I \leq$ & r,T & Y,TY & $r, \Sigma Y$ & Y,0T & $\varepsilon, \ldots$ & $r, O V$ & $r, 0$. & $\mathrm{X} 27$ \\
\hline$r, .$. & 1,91 & $r, r_{1}$ & $r, \ldots$ & $r, r q$ & $r, V I$ & $r, r q$ & $r, r$. & $\mathrm{X} 29$ \\
\hline$r, v q$ & וז, & $1,1 \mathrm{~V}$ & $r, q$. & $1, \leqslant 9$ & $r, v)$ & r,or & ץ,乏. & X1 \\
\hline$r, r$ & r, & $r, Y V$ & $r, \cdot \Lambda$ & Y,YO & r,or & $r, \leqslant \wedge$ & r,Yo & $\mathrm{X} 15$ \\
\hline$r, 91$ & $r, \ldots$ & $r, \cdot \Lambda$ & $r, .0$ & 1,94 & $r, V T$ & $\Gamma, \Sigma \wedge$ & $r, \varepsilon$. & $\mathrm{X} 18$ \\
\hline$r, r v$ & $1, V V$ & $1,9 r$ & $r, 0 \leq$ & $1,7 \mathrm{~V}$ & $r, .7$ & $r, \wedge V$ & $r, V T$ & $\mathrm{X} 23$ \\
\hline$r, r$. & r,^० & $r, \ldots$ & $r, r$. & $r, r q$ & $r, V T$ & $r, V$. & r, . & $\mathrm{X} 3$ \\
\hline$r, 17$ & $\varepsilon, 1 V$ & Y,O. & $r, r q$ & $r, Y \wedge$ & ז, ז, & $r, Y Y$ & ץ,ऍ. & $\mathrm{X5}$ \\
\hline r,91 & $r, \cdot r$ & 1,94 & r, & $r, 1$. & $r, r q$ & $\varepsilon, \vee \wedge$ & $\sum, \Sigma Y$ & $\mathrm{X} 6$ \\
\hline T,TY & $1, \wedge 1$ & 1,94 & $r, I T$ & 1,97 & $r, \leqslant V$ & $r, Y T$ & $r, \wedge r$ & $\mathrm{X} 8$ \\
\hline T,Y $\leq$ & $1, \wedge 1$ & $r, Y V$ & $r, Y r$ & $r, 1$. & $r, .7$ & $r, O r$ & r,o. & $\mathrm{X} 11$ \\
\hline$r, \cdot \varepsilon$ & r,Vo & 1,97 & $r, \cdot r$ & I,Ar & $\varepsilon,+7$ & $r, \wedge V$ & $\Gamma, \wedge$. & $\mathrm{X} 17$ \\
\hline$r, .9$ & $r, r)$ & $r, \leqslant 7$ & $r, r Y$ & r,ז & $r, V V$ & $r, 91$ & r, & X26 \\
\hline$r, r q$ & Y,r & r,70 & $\Gamma, \wedge$. & Y,Ar & $\varepsilon, Y \varepsilon$ & $r, 70$ & $r, 00$ & $\mathrm{X} 28$ \\
\hline$r, \cdot \varepsilon$ & $\varepsilon, \cdot r$ & r,10 & $r, \cdot v$ & r,IV & $r, V I$ & T,97 & $r, r \mu$ & $\mathrm{X} 12$ \\
\hline$r, \wedge$. & $Y, \cdot \Sigma$ & 4,19 & r,^० & $1, v \leq$ & $\Gamma, V \tau$ & $\Gamma, \Sigma \wedge$ & r,or & X13 \\
\hline$r, \ldots$ & $\Gamma, \wedge \Gamma$ & $1, \wedge \wedge$ & $r, \cdot r$ & $r, \wedge I$ & $r, Y \leq$ & $r, . q$ & $r, 1 T$ & $\mathrm{X} 19$ \\
\hline T,TY & $T, \cdot Y$ & $1, \wedge 0$ & $r, \cdot r$ & $1, \times 9$ & $r, I T$ & r, & $r, 10$ & $\mathrm{X} 20$ \\
\hline$r, V V$ & $r, v q$ & $1, \wedge 1$ & r,VA & $1, V Y$ & $r, Y \varepsilon$ & $r, \cdot \varepsilon$ & $r, q r$ & $\mathrm{X} 22$ \\
\hline$r, 7 \wedge$ & r,q & $1, \wedge \wedge$ & $r, 1$. & 1,70 & T,^Y & $r, v$. & $r, V \cdot$ & $\mathrm{X} 24$ \\
\hline$r, 09$ & $r, \Sigma Y$ & 1,97 & $r, .0$ & $r, . \tau$ & r,Or & $r, v$. & T,乏. & X30 \\
\hline$r, \wedge \wedge$ & Y,OV & $r, .0$ & $r, . q$ & $r, 1 \wedge$ & $r, \leqslant q$ & $r, \leqslant V$ & r.,. & لمستوسط للمجي \\
\hline
\end{tabular}

الجدول من إعداد الباحثين اعتمادًا على مخرجات التحليل الإحصائي باستخدام الحزمة (SPSS). 
ويعزز ذلك نتائج اختبار (Scheffe) للمقارنات البعدية كما يتضح من

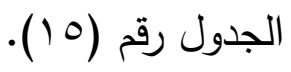

جدول (0) (10). نتائج اختبار (Scheffe) لتتبع معنوية الفروق تبعا للجامعات.

\begin{tabular}{|c|c|c|c|c|c|c|c|c|}
\hline الجامعة & رقم (؟) الجامعة & رقت (•) & رقم (ع ) & رقا (r) الجامعة & رقا (r) الجامعة & رقا (1) & الحسابي & الجامعات \\
\hline$*, \ldots$ & $*,, \ldots$ & & $*, \ldots$ & & & & $\begin{array}{l}r \varepsilon, v \\
r v, \tau \\
r l, \wedge\end{array}$ & رقم (1) \\
\hline$*$ & $*, \ldots$ & & $* \ldots$ & & & & $\begin{array}{l}r q, q \\
\varepsilon r, 0 \\
r q, v\end{array}$ & رقم (ץ) \\
\hline$*$ & $* \ldots$ & & $* \ldots$ & & & & $\begin{array}{l}\xi Y, \varepsilon \\
\leqslant 0, r \\
Y q, 0\end{array}$ & رقم (r) \\
\hline$*, \ldots$ & & & $*, \ldots$ & $*, \ldots$ & $*, \ldots$ & $* \ldots$ & $\begin{array}{l}-r \leqslant, v \\
-r q, q \\
-\varepsilon r, \varepsilon \\
-r q, q \\
-1 r, q\end{array}$ & رقم (ع الجامعة \\
\hline$*, \ldots$ & $*$ & & $* \ldots$ & & & & $\begin{array}{l}r q, V \\
r Y, Y \\
1 \%, \wedge\end{array}$ & رقم (0) \\
\hline \multirow[t]{2}{*}{$* \ldots$} & & $*, \ldots$ & & $*, \ldots$ & $*, \ldots$ & $* \ldots$ & $\begin{array}{l}-r v, \uparrow \\
-\varepsilon r, 0 \\
-\varepsilon 0, r \\
-r r, \uparrow \\
-10, \Lambda\end{array}$ & رقم (†) الجامعة \\
\hline & $*$ & $*, \ldots$ & $*, \ldots$ & $*, \ldots$ & $*,, \ldots$ & $*, \ldots$ & $\begin{array}{l}-r 1,1 \\
-r q, 7 \\
-r q, 0 \\
-1 r, 9 \\
-17,1 \\
-10,1\end{array}$ & رقم (v) \\
\hline
\end{tabular}

الجدول من إعداد الباحثين اعتمادًا على مخرجات التحليل الإحصائي باستخدام الحزمة (SPSS). 
الاستنتاجات

خلصت الدراسة إلى مجموعة من النتائج لعل أبرزها:

أولاً: أن معظم الجامعات السعودية محل الدراسة تعاني من وجود معوقات للتخطيط الاستراتيجي فيها، وتتقق هذه الدراسة مع العديد من الدراسات التي (Feldman and March, 1981, Rawely et al., أجريت في جامعات أخرى كدراسات 1997, Steeples, 1997, Shulok and Harrison, 1998, Meesilapavikkai, 2000, .(Hunt et al. 1997, Schmiditlein, 1995

ثانيًا: أن المعوقات ذات العلاقة بالبعد الإداري والتنظيمي وبالبعد البشري تأتي في مقدمة معوقات التخطيط الاستراتيجي في الجامعات السعودية، وتتثق هذه النتيجة مع ما توصلت إليه دراسات الكلثمة وبدران (r ا • rم) التي توصلت إلى أن المعوقات الإدارية المتمثلة بالبيروقراطية والروتين الإداري تعد من أبرز معوقات التخطيط الاستراتيجي في جامعة أم القرى، كما تتفق مع نتائج دراسة شرف وآخرون

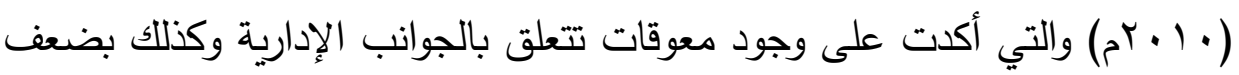
ثقافة العاملين في الجامعات بالتخطيط الاستراتيجي. في حين تأتي المعوقات ذات العلاقة بالبعد المالي في مؤخرة ترتيب المعوقات، بل أنها لا تمثل معوقات بالنسبة لبعض الجامعات، وهذه النتيجة تختلف مع نتيجة دراسة (Cowburn, 2005) في المملكة المتحدة التي أكدت على أن الجامعات البريطانية لا تمارس عمليات التخطيط الاستراتيجي وذلك عائد بدرجة أساسية إلى قلة الموارد المالية، لكنها تعود وتتقارب مع ما توصلت إليه هذه الدراسة من أن هناك معوقات أخرى تتمثل في ازدواجية القرارات وهي معوقات إدارية. لكنها تختلف مع نتائج دراسة شرف وآخرون (· • ( ام) التي تشير إلى أن نقص الموارد في الجامعات السورية يعد معوقًا أساسيًا من معوقات التخطيط الاستراتيجي. كما تتقق نتائج هذه الدراسة إلى حد ما مع ما توصلت إليه نتائج دراسة (Tagis, 2002) التي اعتبرت أن المعوق الرئيس للتخطيط 
الاستراتيجي يتمثل في ضعف الصلاحيات الوظيفية، وبالتالي ضعف المسؤولية الالتزامية للأفراد القائمين على التخطيط الاستراتيجي وتتفيذه.

ثالثًا: تختلف القيادات الجامعية في نظرتها نحو الأسباب المعيقة للتخطيط الاستراتيجي، فالقيادات الشابة تضع وزنًا أكثر لهذه الأسباب عن نظرائهم القيادات الأكبر عمرًا.

رابعًا: تختلف القيادات الجامعية في نظرتها نحو الأسباب المعيقة للتخطيط الاستراتيجي، حيث يضع مديرو ووكلاء الجامعات وزنًا أقل لهذه الأسباب عن نظرائهم عمداء الكليات والعمادات المساندة ومديرو العموم.

خامسًا: تختلف القيادات الجامعية في نظرتها نحو الأسباب المعيقة للتخطيط الاستراتيجي حسب عدد سنوات العمل التي أمضوها في وظائفهم الحالية، حيث تنزع القيادات الجامعية التي أمضت وقتًا أطول في مناصبها إلى وضع وزن أكثر لهذه الأسباب عن نظرائهم الذين أمضوا وقتًا أقصر في مناصبهم. وهذه النتيجة تختلف مع نتائج دراستي الكلثم وبدران (r ( •rم) وشرف وآخرون

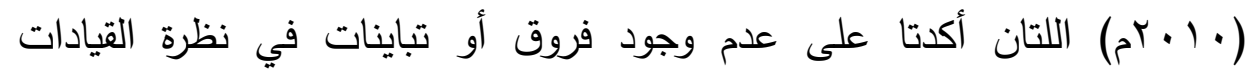
الجامعية لمعوقات التخطيط الاستراتيجي وفقا لمتغير الخبرة. سادسًا: أن معوقات التخطيط الاستراتيجي ودرجة تلك المعوقات تختلف من جامعة إلى أخرى، فهناك جامعات تظهر فيها المعوقات بدرجة كبيرة، في حين تظهر تلك المعوقات بدرجة منخفضة في جامعات أخرى.

التوصيات

بناء على النتائج التي تم استعراضها فهناك مجموعة من التوصيات نوردها 
• ضرورة اهتمام قيادة الجامعات السعودية بالتخطيط الاستراتيجي، وإعداد خطط استراتيجية مبنية على المنهجية العلمية في التخطيط الاستراتيجي القائم على بلى باتئه إعداد وصياغة الرؤيا والرسالة، ووضع الأهداف بناء على تحليل البيئة المحيطة وتحديد الفرص والتهديدات فيها مع تحديد نقاط القوة والضعف الداخلي ومن ثم تحديد الوسائل والأساليب الموصلة إلى تحقيق تلك الأهداف، مع وضع معايير لقياس مدى تحقق الأهداف وتتفيذ الخطة الاستراتيجية.

• العمل على إزالة معوقات التخطيط الاستراتيجي في الجامعات السعودية والتي يأتي على رأسها المعوقات ذات العلاقة بالبعد الإداري والتتظيمي وبالبعد البشري، وذلك من خلال تخفيف المركزية ومنح الصلاحيات للكليات والوحدات التابعة للجامعة. • العمل على تدريب منسوبي الجامعة على التخطيط الاستراتيجي، وزيادة الدورات التخصصية في هذا المجال، كي يتمكنوا من خوض غمار تجربة التخطيط الاستراتيجي وهم يمتلكون المهارات والقدرات الخاصة بعملية التخطيط الاستراتيجي. • العمل على نشر ثقافة التخطيط الاستراتيجي داخل الجامعات والعمل على عقد الندوات وورش العمل الخاصة بذللك، واستعراض النماذج الناجحة والنموذجية والمتميزة في التخطيط الاستراتيجي سواء على مستوى الوحدات الداخلية للجامعات، أو على مستوى الجامعات المماثلة في المملكة، أو على مستوى جامعات خارجية عربية أو أجنبية.

• ضرورة التزام قادة الجامعات ومسؤولوا الإدارة العليا بتتفيذ الخطط الاستراتيجية، وتقديم نموذج يحتذى به من قبل بقية منسوبي الجامعة. • مراجعة الأنظمة والإجراءات واللوائح الخاصة بالصرف من ميزانية الجامعات والمناقلة بين بنودها المختلفة مما يسهل تمويل الخطط الاستراتيجية حسب ما تقتضيه المصلحة وحسب التغييرات والتحولات المحيطة. 
• تفعيل أدوات ووسائل الاتصال وتطوير نظم المعلومات داخل الجامعات، وتحديث المعلومات سواء كانت داخلية أو خارجية بصورة مستمرة، بما يساعد على وتهوير تبادل المعلومات بين أطراف الجامعة، وبالتالي تبادل الآراء وحل الإشكاليات، والتغلب على المعوقات التي تمنع الجامعات من التخطيط الاستراتيجي. • محاولة الاستفادة من النماذج والتجارب المتعددة في التخطيط الاستراتيجي، واعتماد أكثر النماذج سهولة ومناسبة للجامعات السعودية خاصة تللك التي يراعى فيها قصر الوقت المستغرق للتخطيط، فضلا عن انخفاض الكلفة.

يتقدم فريق الدراسة بالثكر لعمادة البحث العلمي، جامعة الملك عبدالعزيز -

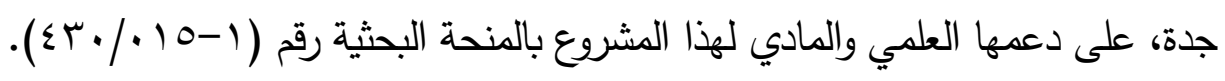

\section{المراجع}

أولاً: المراجع العربية

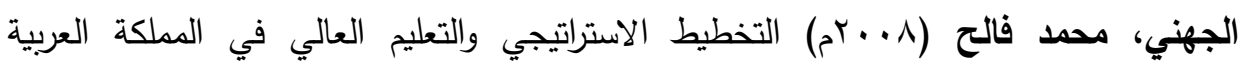
السعودية، بحث منشور على شبكة الإنترنت في الموقع: www.almarefah.org/new, php

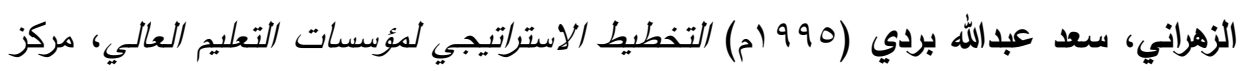
البحوث التربوية والنفسية بجامعة أم القرى.

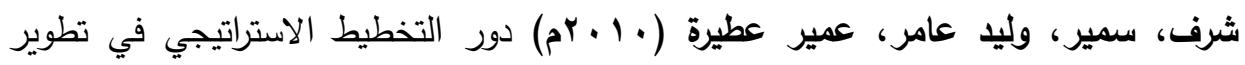

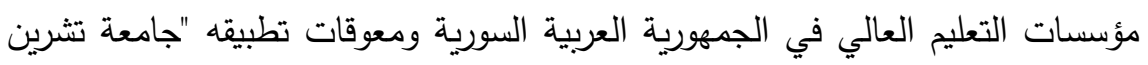

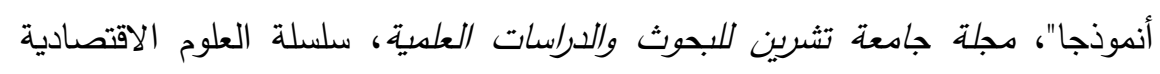

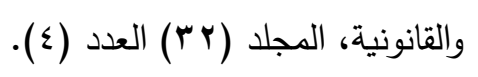

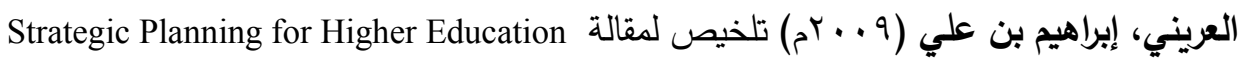
in Developing countries : Challenges and Lessons الصادرة عن جامعة الملك سعود بالرياض، ومتاحة على الموقع الإلكتروني: http://www.ksu.edu.sa/sites/KSUArabic/UMessage/archive 


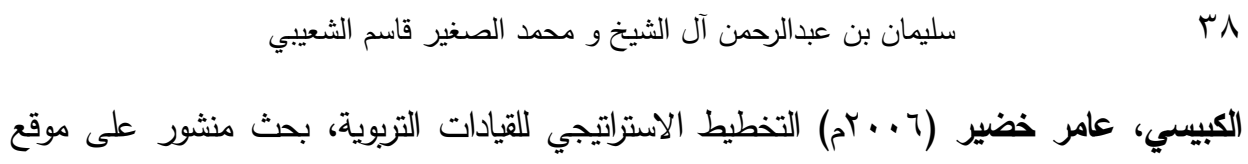

جامعة نايف العربية للعلوم الأمنية: http://www.nauss.edu.sa/DocLib1/takhtetistrategy1.pdf

الكلثم، حمد بن مرضي وبارن، حازم علي أحمد (r ( ب م) معوقات التخطيط الاستراتيجي في

جامعة أم القرى من وجهة نظر أعضاء هيئة التدريس فيها، المجلة العربية لضمان جودة

التعليم الجامعي، المجلد (0) العدد (• ( ).

ثانيًا: المراجع الإنجليزية

Castells, M. (2001) The New Global Economy. In J. Muller, N. Cloetta and S. Badat (Eds.), Challenges of Globalisation: South African Debates with Manuel Castells (pp. 2-21). Cape Town, SA: Maskew Miller Longman.

Cater, T. and Pucko, D. (2010) Factors of effective strategy implementation: Empirical evidence from Slovenian business practice. Journal for East European Management Studies. 15(3): 207-236.

Cope, R.G. (1987) Strategic Policy Planning: A Guide for College and University Administrators, Washington, D.C., Ireland Educational Corp.

Cowburn, S. (2005) "Strategic Planning in Higher Education: Fact or Fiction?" Perspective, 9(4): 103-109.

Driscoll, D.P. (2010) Higher Education Planning For a Strategic Goal with a Concept Mapping Process at a Small Private College, A Dissertation Submitted to The University of North Carolina at Greensboro. http//wwwlip.umi.com/dissertations/ fullcit / 3220045

England-Siegerdt Christy Ann. (2006) Faculty Members Experiences with Administration and foundations, Illinois State University.

Feldman, M.S. and March, J.G. (1981) Information in Organization as Signal and Symbol. Administrative Science Quarterly, 26: 111-186.

Gurkov I.B. (2009) Strategy Process as Formulation and Realization of Corporate Goals: the Synthesis of Surveys in Russian Firms, Journal for East European Management Studies, 14(1): 48-64.

Hayward F.M. (2008) Strategic Planning for Higher Education in Developing Countries: Challenges and Lessons, Planning for Higher Education, 36(3): 5-21.

Hrebiniak, L.G. (2008) Making strategy work: Overcoming the obstacles to effective execution, in: Ivey Business Journal Online, 72, 2, 1.

Hunt, C.M., Oosting, K.W., Stevevens, R., Loudon, D. and Migliore, R.H. (1997) Strategic planning for private higher education. NEW york: The Haworth Press.

Ismail, N.A., Ali, R.H., Saat, R.M. and Hsbollah, H.M. (2007) Strategic information systems planning in Malaysian public universities, Campus-Wide Information Systems, 24(5): 331-341.

Johnson R.G. (2000) An Analysis of Strategic Planning in The Auxiliaries of the California State University System, (Ph.D. dissertation, School of Organizational Management, Department of Public Administration).

Keller, G. (1983) Academic Strategy: The Management Revolution in America Higher Education, (Baltimore: Johns Hopkins University Press). 
Ko Vicki W.K. (1990) Strategic Planning as Perceived by Chief Administrations of Four-Year Higher Education Institutions in the Great Lakes Region, (Ph.D. dissertation, Indiana State University).

Kwiek, M. (2003) The State, the Market and Higher Education: Challenges for the New Century, in M. Kwiek (ed.) The University, Globalization, Central Europe, New York: Peter Lange.

Machadoa, M.L., Farhangmehrb, M. and Taylor, J.S. (2004) The Status of Strategic Planning in Portuguese Higher Education Institutions: Trappings or Substance?, Higher Education Policy, 17: 383-404.

Manning, L.A. (1991) Strategic Planning Process for Multi-Campus University System: The Role of One Campus and its Library. Journal of Library Administration, 13(3/4): 181-1991.

Meesilapavikkai, K. (2000) The Status of Strategic Planning at Public and Private Universities in Thailand, (Ph.D. dissertation, Gruduate Faculty of The School of Education).

Meredith, M. (1993) What Works and Doesn't in Planning, Planning for Higher Education, 22(1): 28-30.

OECD (2002) Education at a Glance: OECD Indicators 2002, Paris: OECD.

Rowely, D.J., Lujan, H.D. and Dolence, M.G. (1997) Strategic Change in Colleges and Universities: Planning to Survive and Prosper, (San Francisco: Jossey-Bass Inc).

Sadlak, J. (2000) Globalization versus the universal role of the university, Higher Education in Europe 25: 2.

Schmidtlein, F. (1995) Responding to Diverse Institutional Issues: Adapting Strategic Planning Concepts, New Directions for Institutional Research, 67: 83-93.

Shulok, N. and Harrison, M.E. (1998) Integrating Planning Assessment and Resource Allocation, Planning for Higher Education, 26(3): 29-37.

Steeples, D.W. (1997) Successful Strategic Planning Case Studies. New Directions for Higher Education, 64: 67-78.

Tagis W.G. (2002) Assessing Strategic Planning for Modernization Papua New Guinea's Public Universities, (Ph.D. dissertation, Faculty of the Graduate School of the University of Minnesota).

Teo, T.S.H. and Ang, J.S.K. (2001) An examination of major IS planning problems, International Journal of Information Management, 21(6): 457-470.

Wilkins, J.C. (2006) Participant Perception of Strategic Planning in an Urban School District: A Case Study, (Ph.D. dissertation, Cardinal Stritch University).

Williams, J. (1991) Strategic Planning in Higher Education, New York: Haworth Press.

Yaakub, N.A., Saat, R.M. and Ali, R.H.R.M. (2005) Strategic Information System Planning (SISP) in Private Universities in Malaysia: An Exploratory Study, Proceedings of International Conference on E-Commerce 2005, pp. 226-230. 


\title{
Obstacles to Strategic Planning in Saudi Universities
}

\author{
Sulaiman A. Al-Ahlsheik \\ Assistant Professor \\ Department of Business Administration \\ Faculty of Economics and Administration \\ King Abdulaziz University, Jeddah, Saudi Arabia \\ Mohammed A. Al-Shaebi \\ Associate Professor \\ Department of Business Administration, Community College \\ King Khalid University, Abha, Saudi Arabia
}

\begin{abstract}
The purpose of this study is to identify the obstacles and difficulties of strategic planning in Saudi universities. It determines the level of agreement/disagreement of administrative leadership with respect to those identified obstacles. A research study is conducted on a model, consisting of 30 items that represent the major obstacles to strategic planning identified by previous research studies. Data is collected from Saudi Universities that were established prior to the year 2000. The sample size is (285) subjects who represent university presidents, university vice presidents, deans, and general managers.
\end{abstract}

Results suggest many obstacles that hinder strategic planning in Saudi universities. However, effects of these obstacles differ from one university to the other. In addition, both administrative and human obstacles are considered more important than financial obstacles. The study recommends some solutions to Saudi universities in order to overcome those obstacles. 